\title{
Dynamical and Thermodynamical Causes of Large-Scale Changes in the Hydrological Cycle over North America in Response to Global Warming*
}

\author{
RICHARD SEAGER \\ Lamont-Doherty Earth Observatory of Columbia University, Palisades, New York \\ DAVID NEELIN \\ Department of Atmospheric Sciences, University of California at Los Angeles, Los Angeles, California \\ Isla Simpson, Haibo LiU, NaOmi Henderson, Tiffany Shaw, Yochanan Kushnir, \\ AND MingFANG TING \\ Lamont-Doherty Earth Observatory of Columbia University, Palisades, New York \\ BENJAMIN COOK \\ NASA Goddard Institute for Space Studies, New York, New York
}

(Manuscript received 21 February 2014, in final form 16 July 2014)

\begin{abstract}
The mechanisms of model-projected atmospheric moisture budget change across North America are examined in simulations conducted with 22 models from phase 5 of the Coupled Model Intercomparison Project. Modern-day model budgets are validated against the European Centre for Medium-Range Weather Forecasts Interim Re-Analysis. In the winter half year transient eddies converge moisture across the continent while the mean flow wets the west from central California northward and dries the southwest. In the summer half year there is widespread mean flow moisture divergence across the west and convergence over the Great Plains that is offset by transient eddy divergence. In the winter half year the models project drying for the southwest and wetting to the north. Changes in the mean flow moisture convergence are largely responsible across the west but intensified transient eddy moisture convergence wets the northeast. In the summer half year widespread declines in precipitation minus evaporation $(P-E)$ are supported by mean flow moisture divergence across the west and transient eddy divergence in the Great Plains. The changes in mean flow convergence are related to increases in specific humidity but also depend on changes in the mean flow including increased low-level divergence in the U.S. Southwest and a zonally varying wave that wets the North American west and east coasts in winter and dries the U.S. Southwest. Increased transient eddy fluxes occur even as low-level eddy activity weakens and arise from strengthened humidity gradients. A full explanation of North American hydroclimate changes will require explanation of mean and transient circulation changes and the coupling between the moisture and circulation fields.
\end{abstract}

\section{Introduction}

The North American hydroclimate is marked by stark contrasts with semiarid to arid regions in the U.S.

\footnotetext{
* Lamont-Doherty Earth Observatory Contribution Number 7825 .
}

Corresponding author address: Richard Seager, Lamont-Doherty Earth Observatory of Columbia University, 61 Route 9W, Palisades, NY 10964.

E-mail: seager@ldeo.columbia.edu
Southwest; wet subtropical, temperate, and continental climates to the east and north; and the Great Plains characterized by a remarkably strong west to east dry to wet transition. All model-based analyses of the impacts of rising greenhouse gases on North American climate project that these contrasts will become even more marked in the coming century. This occurs as part of a general amplification of existing patterns of hydroclimate with subtropical regions, including southwestern North America getting drier and expanding poleward, and midlatitude regions, including the northern reaches of the United States and Canada, getting wetter (Held 
and Soden 2006; Solomon et al. 2007; Neelin et al. 2006, 2013; Seager et al. 2007; Seager and Vecchi 2010; Seager et al. 2013; Wehner et al. 2011). The simplest part of this change is the impact of the rise in specific humidity that follows the rise in saturation specific humidity driven by atmospheric warming. In regions of low-level mean flow convergence this will cause an increase in precipitation minus evaporation, $P-E$, and a decrease in $P-E$ in regions of low-level mean flow divergence. This process increases $P-E$ in the intertropical convergence zone and in the regions of eddy-driven mean flow ascent in the midlatitudes and decreases $P-E$ in the subtropics. It is often referred to as the "wet-get-wetter, dry-getdrier" or "rich-get-richer, poor-get-poorer" mechanism (Chou and Neelin 2004; Held and Soden 2006; Chou et al. 2009). However, changes in atmospheric circulation, in particular the poleward expansion of the Hadley cell and poleward shift of storm tracks, are also important (Previdi and Liepert 2007; Seager et al. 2010; Scheff and Frierson 2012) as is the reduction in dynamical measures of the storm track activity such as variance of sea level pressure or meridional velocity (Chang 2013). Local dynamical processes can also play a role, such as strengthening of the Great Plains low-level jet (Cook et al. 2008) in spring.

The purpose of this paper is to thoroughly examine Coupled Model Intercomparison Project (CMIP) phase 5 (CMIP5) model-projected changes over North America and to determine the mix of dynamical and thermodynamical mechanisms that cause the spatially and seasonally varying changes. We have recently completed such an analysis for the Mediterranean region (Seager et al. 2014, hereafter S14) and this is a companion paper in the sense that the analyses are largely the same as used there (albeit on a 22-model ensemble here with 6-hourly data as opposed to the earlier 15-member ensemble with daily data). Recently Sheffield et al. (2013) and Maloney et al. (2014) have examined North American climate and climate change in the CMIP5 multimodel ensemble. Unlike those comprehensive papers, the present paper is more focused on mean hydroclimate and extends that work by analyzing in detail the mechanism of moisture budget change within a 22-model ensemble. Further, Neelin et al. (2013) have examined the CMIP5 models' projection of increasing precipitation over California in the December through February season. This appears to differ from the projections in the earlier CMIP phase 3 (CMIP3) but California lies between regions of greenhouse gas-induced wetting to the north and drying to the south. These are robust projections in both model ensembles but robust predictions are in general challenging at boundaries between large-scale wetting and drying tendencies. Neelin et al. (2013) suggest that a circulation change involving an eastward extension of the strong part of the subtropical jet, and the associated change in storm-track rainfall over the eastern Pacific, was responsible for the midwinter wetting in CMIP5. The detailed moisture budget analyzed here will address this by considering mechanisms of $P-E$ change across all of North America.

Although climate models indicate that human-induced hydroclimate change should already be underway across North America, it is likely currently masked by natural variability of climate. The ongoing drought in western North America, for example, is likely highly influenced by natural decadal variability, especially in the Pacific Ocean, as well as internal atmospheric variability (Hoerling et al. 2010; Seager and Vecchi 2010; Hoerling et al. 2014). Similarly, a strong trend toward wetter conditions in the northeastern United States cannot be easily attributed to human-induced climate change and instead is likely influenced by natural climate variability (Seager et al. 2012b). Despite ongoing climate variability, there is little doubt that, across North America, human-induced hydroclimate change will intensify and need to be adapted to. However, adaptation efforts will be greatly aided by narrowing of uncertainties in hydroclimate projections. Water resources in the southwestern United States are one example. The Colorado River draws most of its flow from its northern headwaters that lie close to a nodal region between drying to the south and wetting to the north and this, together with other reasons, causes considerable uncertainty in projections of future flow, although the consensus is that it will decline (Vano et al. 2014). Similarly the uncertainty about winter precipitation changes in California (Neelin et al. 2013) leads to uncertainty in changes in Sierra Nevada winter snowpack-another critical element of U.S. Southwest water resources [see MacDonald (2010) and Cayan et al. (2010) for more discussion]. The humid U.S. Southeast has had to contend with both drought and flood in recent years and Li et al. (2012a) project an increase in summer precipitation in the region related to an expansion of the North Atlantic subtropical high although this could be offset by higher evapotranspiration (Seager et al. 2009).

Determining the uncertainty in the projections requires not just analysis of the variation among the model projections but also an assessment of why the changes occur. We then need to consider whether the physical mechanisms of model-projected hydroclimate change are properly representing processes in the real climate system or, alternatively, depend on some uncertain or poorly represented components of the model. Such information will not only be of use in determining uncertainties of projections but also can guide efforts to improve models and narrow uncertainties. The work presented here aims to move our understanding in this direction. 


\section{Reanalyses and CMIP5 model data}

The climate models will be validated against the European Center for Medium-Range Weather Forecasts (ECMWF) Interim Re-Analysis (ERA-Interim, herein ERA-I), which covers from 1979 to the present (Berrisford et al. 2011a,b; Dee et al. 2011). ERA-I is the most recent of the ECMWF reanalyses and, relative to its precursors, has an improved representation of the hydrological cycle resulting from assimilation of cloud and rain-affected satellite irradiances. It is based on an atmospheric model and reanalysis system with 60 levels in the vertical with a top level at $0.1 \mathrm{mb}(1 \mathrm{mb}=1 \mathrm{hPa})$, a T255 spherical harmonic representation, and, for surface and grid point fields, a reduced Gaussian grid with about a 79-km spacing (Berrisford et al. 2011b). However, the analyses performed here are with data archived by ECMWF on a regular $1.5^{\circ}$ grid with 37 model levels and at 6-hourly resolution. All calculations were performed as in Seager and Henderson (2013, hereafter SH). SH provide a thorough analysis of errors introduced by choice of numerical methods and the temporal and spatial resolution of the reanalysis data (see also S14).

For the CMIP5 models (Taylor et al. 2012) we analyzed the historical simulations and future projections with the representative concentration pathway 8.5 (RCP8.5) emissions scenario. RCP8.5 is the highemissions member of the scenarios and its choice is justified by the current lack of international action to limit greenhouse gas emissions. To provide the most accurate assessment of model moisture budgets possible, we made use of the archived 6-hourly hybrid-sigma coordinate data for the calculation of transient flux terms. There were 22 models for which these data were available, the details of which (including expansions of model names) are provided in Table 1. Altogether 41 simulations were analyzed for the historical period and 24 for the future period. ${ }^{1}$ Moisture budgets were computed for each model simulation. An ensemble mean was then computed for each model followed by the multimodel ensemble. To create the multimodel ensemble, model data were regridded to a common $1^{\circ} \times 1^{\circ}$ grid. Identical methods were used for the models as for ERA-I and are detailed in SH.

\footnotetext{
${ }^{1}$ Note that S14 used daily data for which more simulations were available than for the 6-hourly data used here: 6-hourly data, which allow a better estimate of transient eddy moisture fluxes than daily data (see $\mathrm{SH}$ ), were used here in response to a reviewer's concern about the accuracy of the moisture budget. The trade-off of improved accuracy of calculations for a single simulation versus fewer model simulations available should be borne in mind. However, all conclusions derived here can also be drawn based on analysis of daily data.
}

Since we are interested in the near-term future of relevance to adaptation, we examine the future 2021-40 period and compare this to the 1979-2005 period for which the ERA-I data and the CMIP5 historical simulations overlap.

\section{Moisture budget analysis methods}

The analysis methods are those of SH where they are described in full detail. The description below is brief and closely follows that in S14. Since, the CMIP5 data archive most readily provides model data on pressure levels rather than the model native vertical grid, we will work in pressure coordinates for which the steady-state moisture budget is

$$
P-E=-\frac{1}{g \rho_{w}} \nabla \cdot \int_{0}^{p_{s}} \mathbf{u} q d p,
$$

where $P$ is precipitation, $E$ is evaporation or evapotranspiration, $g$ is the acceleration due to gravity, $\rho_{w}$ is the density of water, $p$ is pressure and $p_{s}$ its surface value, $q$ is specific humidity, and $\mathbf{u}$ is the vector of horizontal velocity. The notation follows that of SH and of Seager et al. (2012a) and S14. The vertical integral is performed as a sum over pressure levels so Eq. (1) is replaced with

$$
P-E=-\frac{1}{g \rho_{w}} \nabla \cdot \sum_{k=1}^{K} \mathbf{u}_{k} q_{k} d p_{k},
$$

where $k$ refers to vertical level of which there are $K$ total and $d p_{k}$ is the pressure thickness of each level with the lowest level extending to $p_{s}$.

To determine the climatological budget we divide all quantities into monthly means, represented by overbars, departures from monthly means, represented by primes, and climatological monthly means, represented by double overbars. Then Eq. (2) can be rewritten as

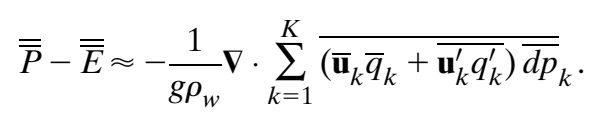

Here the first and second terms on the right-hand side are the moisture convergence by the mean flow and submonthly transient eddies, respectively. The approximation is because of ignoring terms involving $d p_{k}^{\prime}$, which is acceptable (see SH). Separated in this way the mean flow term includes contributions from both the climatological mean flow combining with the climatological mean humidity and covariances of monthly mean anomalies of flow and humidity. The latter term is essentially the rectified effect on the mean climatological hydroclimate of monthly and longer time scale atmospheric variability. This term is in general small relative to the climatological and transient eddy terms, except in far southwestern North America. For interest, the climatology and variability breakdown of the mean term is shown in appendix B. 
TABLE 1. CMIP5 models used in this study with information on host institute, model, grid resolution (T refers to triangular truncation, $\mathrm{C}$ refers to cubed sphere and, L refers to number of vertical levels), and ensemble sizes [20C denotes the twentieth-century (historical) simulations].

\begin{tabular}{|c|c|c|c|c|}
\hline \multirow[b]{2}{*}{ Institute } & \multirow[b]{2}{*}{ Model (expansion) } & \multirow{2}{*}{$\begin{array}{l}\text { Resolution } \\
(\text { lon } \times \text { lat }), \text { levels }\end{array}$} & \multicolumn{2}{|c|}{$\begin{array}{l}\text { Ensemble } \\
\text { size }\end{array}$} \\
\hline & & & $20 \mathrm{C}$ & RCP8.5 \\
\hline \multirow[t]{2}{*}{ Beijing Climate Center (BCC) } & $\begin{array}{l}\text { 1. BCC_CSM1.1 (BCC Climate } \\
\text { System Model, version 1.1) }\end{array}$ & T42, L26 & 1 & 1 \\
\hline & $\begin{array}{l}\text { 2. BCC_CSM1.1-m [BCC_CSM1.1 } \\
\text { (moderate resolution)] }\end{array}$ & T106, L26 & 1 & 1 \\
\hline $\begin{array}{l}\text { College of Global Change and } \\
\text { Earth System Science, Beijing } \\
\text { Normal University (BNU) }\end{array}$ & $\begin{array}{l}\text { 3. BNU-ESM (BNU Earth System } \\
\text { Model) }\end{array}$ & T42, L26 & 1 & 1 \\
\hline $\begin{array}{l}\text { Canadian Centre for Climate } \\
\text { Modelling and Analysis } \\
\text { (CCCma) }\end{array}$ & $\begin{array}{l}\text { 4. CanESM2 (Second Generation } \\
\text { Canadian Earth System Model) }\end{array}$ & T63 $\left(1.875^{\circ} \times 1.875^{\circ}\right), \mathrm{L} 35$ & 1 & 1 \\
\hline $\begin{array}{l}\text { National Center for } \\
\text { Atmospheric Research (NCAR) }\end{array}$ & $\begin{array}{l}\text { 5. CCSM4 (Community Climate } \\
\text { System Model, version 4) }\end{array}$ & $288 \times 200\left(1.25^{\circ} \times 0.9^{\circ}\right), \mathrm{L} 26$ & 1 & 1 \\
\hline $\begin{array}{l}\text { Centro Euro-Mediterraneo per I } \\
\text { Cambiamenti Climatici (CMCC) }\end{array}$ & $\begin{array}{l}\text { 6. CMCC-CM (CMCC Climate } \\
\text { Model) }\end{array}$ & T159, L31 & 1 & 1 \\
\hline $\begin{array}{l}\text { Centre National de Recherches } \\
\text { Météorologiques (CNRM)/Centre } \\
\text { Européen de Recherche et de } \\
\text { Formation Avancée en Calcul } \\
\text { Scientifique (CERFACS) }\end{array}$ & $\begin{array}{l}\text { 7. CNRM-CM5 (CNRM Coupled } \\
\text { Global Climate Model, version 5) }\end{array}$ & $\mathrm{T} 127\left(1.4^{\circ} \times 1.4^{\circ}\right), \mathrm{L} 31$ & 1 & 1 \\
\hline $\begin{array}{l}\text { Commonwealth Scientific and } \\
\text { Industrial Research } \\
\text { Organization (CSIRO) in } \\
\text { collaboration with the } \\
\text { Queensland Climate Change } \\
\text { Centre of Excellence (QCCCE) }\end{array}$ & $\begin{array}{l}\text { 8. CSIRO Mk3.6.0 (CSIRO Mark, } \\
\text { version 3.6.0) }\end{array}$ & $\mathrm{T} 63\left(1.875^{\circ} \times 1.875^{\circ}\right), \mathrm{L} 18$ & 1 & 1 \\
\hline $\begin{array}{l}\text { Institute of Atmospheric Physics, } \\
\text { Chinese Academy of Sciences, } \\
\text { and Tsinghua University } \\
\text { (LASG-CESS) }\end{array}$ & $\begin{array}{l}\text { 9. FGOALS-g2 (Flexible Global } \\
\text { Ocean-Atmosphere-Land System } \\
\text { Model gridpoint, version 2) }\end{array}$ & $128 \times 60, \mathrm{~L} 26$ & 2 & 1 \\
\hline \multirow{3}{*}{$\begin{array}{l}\text { National Oceanic and } \\
\text { Atmospheric Administration } \\
\text { (NOAA)/Geophysical Fluid } \\
\text { Dynamics Laboratory (GFDL) }\end{array}$} & $\begin{array}{l}\text { 10. GFDL CM3 (GFDL Climate } \\
\text { Model, version 3) }\end{array}$ & $\mathrm{C} 48\left(2.5^{\circ} \times 2.0^{\circ}\right), \mathrm{L} 48$ & 5 & 1 \\
\hline & $\begin{array}{l}\text { 11. GFDL-ESM2G (GFDL Earth } \\
\text { System Model with Generalized } \\
\text { Ocean Layer Dynamics } \\
\text { (GOLD) component }\end{array}$ & $144 \times 90\left(2.5^{\circ} \times 2.0^{\circ}\right), \mathrm{L} 24$ & 1 & 1 \\
\hline & $\begin{array}{l}\text { 12. GFDL-ESM2M (GFDL Earth } \\
\text { System Model with Modular } \\
\text { Ocean Model version } 4 \\
\text { (MOM4) component) }\end{array}$ & $144 \times 90\left(2.5^{\circ} \times 2^{\circ}\right), \mathrm{L} 24$ & 1 & 1 \\
\hline \multirow[t]{2}{*}{$\begin{array}{l}\text { National Aeronautics and Space } \\
\text { Administration (NASA) Goddard } \\
\text { Institute for Space Studies (GISS) }\end{array}$} & $\begin{array}{l}\text { 13. GISS-E2-H [GISS Model E2, } \\
\text { coupled with the Hybrid Coordinate } \\
\text { Ocean Model (HYCOM)] }\end{array}$ & $144 \times 90\left(2.5^{\circ} \times 2^{\circ}\right), \mathrm{L} 40$ & 1 & 1 \\
\hline & $\begin{array}{l}\text { 14. GISS-E2-R (GISS Model E2, } \\
\text { coupled with the Russell ocean } \\
\text { model) }\end{array}$ & $144 \times 90\left(2.5^{\circ} \times 2^{\circ}\right), \mathrm{L} 40$ & 1 & 1 \\
\hline \multirow[t]{3}{*}{$\begin{array}{l}\text { Institute Pierre-Simon Laplace } \\
\quad \text { (IPSL) }\end{array}$} & $\begin{array}{l}\text { 15. IPSL-CM5A-LR (IPSL Coupled } \\
\text { Model, version 5A, low resolution) }\end{array}$ & $96 \times 96\left(3.75^{\circ} \times 1.875^{\circ}\right), \mathrm{L} 39$ & 6 & 3 \\
\hline & $\begin{array}{l}\text { 16. IPSL-CM5A-MR (IPSL Coupled } \\
\text { Model, version 5A, mid resolution) }\end{array}$ & $144 \times 144\left(2.5^{\circ} \times 1.25^{\circ}\right)$, L39 & 2 & 1 \\
\hline & $\begin{array}{l}\text { 17. IPSL-CM5B-LR (IPSL Coupled } \\
\text { Model, version 5B, low resolution) }\end{array}$ & $96 \times 96\left(3.75^{\circ} \times 1.875^{\circ}\right)$, L39 & 1 & 1 \\
\hline
\end{tabular}




\begin{tabular}{|c|c|c|c|c|}
\hline \multirow[b]{2}{*}{ Institute } & \multirow[b]{2}{*}{ Model (expansion) } & \multirow{2}{*}{$\begin{array}{l}\text { Resolution } \\
(\text { lon } \times \text { lat }), \text { levels }\end{array}$} & \multicolumn{2}{|c|}{$\begin{array}{l}\text { Ensemble } \\
\text { size }\end{array}$} \\
\hline & & & $20 \mathrm{C}$ & RCP8.5 \\
\hline $\begin{array}{l}\text { Atmosphere and Ocean Research } \\
\text { Institute (AORI, The University } \\
\text { of Tokyo), National Institute for }\end{array}$ & $\begin{array}{l}\text { 18. MIROC5 [Model for } \\
\text { Interdisciplinary Research on } \\
\text { Climate (MIROC), version 5] }\end{array}$ & $\mathrm{T} 85, \mathrm{~L} 40$ & 5 & 1 \\
\hline $\begin{array}{l}\text { Environmental Studies (NIES), } \\
\text { and Japan Agency for }\end{array}$ & $\begin{array}{l}\text { 19. MIROC-ESM (MIROC, Earth } \\
\text { System Model) }\end{array}$ & T42, L80 & 3 & 1 \\
\hline $\begin{array}{l}\text { Marine-Earth Science and } \\
\text { Technology (JAMSTEC) }\end{array}$ & $\begin{array}{l}\text { 20. MIROC-ESM-CHEM (MIROC, } \\
\text { Earth System Model, Chemistry } \\
\text { Coupled) }\end{array}$ & T42, L80 & 1 & 1 \\
\hline $\begin{array}{l}\text { Meteorological Research Institute } \\
\text { (MRI) }\end{array}$ & $\begin{array}{l}\text { 21. MRI-CGCM3 (MRI Coupled } \\
\text { Atmosphere-Ocean General } \\
\text { Circulation Model, version 3) }\end{array}$ & $\operatorname{TL} 159\left(1.125^{\circ} \times 1.125^{\circ}\right)$, L48 & 1 & 1 \\
\hline Norwegian Climate Centre (NCC) & $\begin{array}{l}\text { 22. NorESM1-M [Norwegian Earth } \\
\text { System Model, version } 1 \\
\text { (intermediate resolution)] }\end{array}$ & $144 \times 96\left(2.5^{\circ} \times 1.875^{\circ}\right), \mathrm{L} 26$ & 3 & 1 \\
\hline
\end{tabular}

The mean flow contribution can be broken down into a term related to mass divergence (and hence vertical motion) and a term related to advection across moisture gradients. To do this the divergence operator has to be taken inside the vertical summation which, in addition to the divergence and advection terms, introduces a surface term, namely,

$$
\begin{aligned}
& \overline{\bar{P}}-\overline{\bar{E}} \approx-\frac{1}{g \rho_{w}}\left[\sum_{k=1}^{K} \overline{\left(\overline{\mathbf{u}}_{k} \cdot \nabla \bar{q}_{k}+\bar{q}_{k} \boldsymbol{\nabla} \cdot \overline{\mathbf{u}}_{k}\right) \overline{d p}_{k}}\right. \\
& \left.+\nabla \cdot \sum_{k=1}^{K} \overline{\overline{\mathbf{u}_{k}^{\prime} q_{k}^{\prime}}} \overline{\overline{d p}}_{k}\right]-\frac{1}{g \rho_{w}} \overline{\overline{q_{s} \mathbf{u}_{s} \cdot \nabla p_{s}}} .
\end{aligned}
$$

To represent a difference between twenty-first-century (subscript 21) and twentieth-century (subscript 20) quantities we introduce

$$
\Delta(\cdot)=(\cdot)_{21}-(\cdot)_{20} \cdot
$$

Substituting this into Eqs. (3) and (4) we get the following:

$$
\begin{aligned}
& \Delta \overline{\bar{P}}-\Delta \overline{\bar{E}} \approx-\frac{1}{g \rho_{w}} \nabla \cdot \sum_{k=1}^{K} \Delta\left(\overline{\overline{\mathbf{u}}}_{k} \bar{q}_{k} \overline{\overline{d p}}_{k}\right) \\
& -\frac{1}{g \rho_{w}} \nabla \cdot \sum_{k=1}^{K} \Delta\left({\overline{\overline{\mathbf{u}_{k}^{\prime} q_{k}^{\prime}}}}_{\overline{d p}}^{k}\right)
\end{aligned}
$$

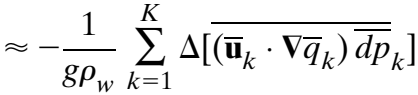

$$
\begin{aligned}
& -\frac{1}{g \rho_{w}} \sum_{k=1}^{K} \Delta\left(\overline{\bar{q}_{k} \nabla \cdot \overline{\mathbf{u}}_{k} \overline{d p}_{k}}\right) \\
& -\frac{1}{g \rho_{w}} \nabla \cdot \sum_{k=1}^{K} \Delta\left({\overline{\overline{\mathbf{u}_{k}^{\prime} q_{k}^{\prime}}} \overline{\overline{d p}}}_{k}\right)-\frac{1}{g \rho_{w}} \Delta\left(\overline{\overline{q_{s} \mathbf{u}_{s} \cdot \nabla p_{s}}}\right) .
\end{aligned}
$$

Changes in the first and second terms of Eq. (7) can arise from either a change in humidity, which is largely, but not entirely, a thermodynamical mechanism, or changes in the circulation, which is a dynamical mechanism (Seager et al. 2010). The thermodynamical and dynamical mechanisms can be diagnostically determined by evaluating the relevant terms holding, first, the circulation and, second, the humidity fixed at their twentieth-century climatological values. The terms related to the moisture advection and the mass divergent flow [the first and second terms in Eq. (7)] are important and can be approximated as

$$
\begin{aligned}
& -\frac{1}{g \rho_{w}} \sum_{k=1}^{K} \Delta\left[{\overline{\left(\overline{\mathbf{u}}_{k} \cdot \nabla \bar{q}_{k}\right) \overline{d p}_{k}}}_{]}\right. \\
& \approx-\frac{1}{g \rho_{w}} \sum_{k=1}^{K} \overline{\overline{\mathbf{u}}}_{k, 20} \cdot \Delta\left(\overline{\nabla \bar{q}_{k} \overline{d p}_{k}}\right) \\
& -\frac{1}{g \rho_{w}} \sum_{k=1}^{K} \nabla \overline{\bar{q}}_{k, 20} \cdot \Delta\left(\overline{\overline{\mathbf{u}}_{k} \overline{d p}_{k}}\right) \quad \text { and } \\
& -\frac{1}{g \rho_{w}} \sum_{k=1}^{K} \Delta\left(\overline{\bar{q}_{k} \nabla \cdot \overline{\mathbf{u}}_{k} \overline{d p}_{k}}\right) \\
& \approx-\frac{1}{g \rho_{w}} \sum_{k=1}^{K} \Delta\left(\overline{\bar{q}}_{k} \overline{d p}_{k}\right) \nabla \cdot \overline{\overline{\mathbf{u}}}_{k, 20} \\
& -\frac{1}{g \rho_{w}} \sum_{k=1}^{K} \overline{\bar{q}}_{k, 20} \Delta\left(\overline{\nabla \cdot \overline{\mathbf{u}}_{k} \overline{d p}_{k}}\right) .
\end{aligned}
$$

Further approximation comes from ignoring terms quadratic in $\Delta$, covariances of anomalous monthly means, and from using the twentieth-century values for $d p_{k}$. In Eqs. (8) and (9) the first terms on the right-hand side (the "thermodynamic" terms) involve the changes 
in humidity while the circulation is fixed and the second terms (the "mean circulation dynamics" terms) involve the changes in the circulation while the humidity is fixed.

The monthly mean data were available on 17 vertical levels and the transient flux terms were calculated using the 6-hourly hybrid-sigma level data after first interpolating onto 18 pressure levels (the standard CMIP5 levels plus $900 \mathrm{mb}$ ) using a log-pressure interpolation. Error in the calculation is analyzed in appendix A where it is shown that these are sufficiently small that the moisture budget and its constituent terms can be diagnosed in a useful way.

For compactness, analysis is done for NovemberApril (NDJFMA) and May-October (MJJASO), termed the winter half year and summer half year, respectively. Definitions of optimal seasons for capturing hydrological cycle behavior may be different among regions and studies, but this roughly captures winter-dominated and summer-dominated hydrological regimes while containing all months. Comparable qualities for the 40-yr ECMWF Re-Analysis (ERA-40) January and July may be seen in SH. Simulated precipitation climatology and global warming changes for June-August and December-February for CMIP5 models may be seen, for example, in Sheffield et al. (2013) and Maloney et al. (2014).

\section{The climatological North American moisture budget in the ERA-I data}

\section{a. The winter half year}

Figure 1 shows the various terms in the North American sector climatological moisture budget according to ERA-I for the winter half year (NovemberApril). In this half year there are $P$ maxima along the west coast of North America and stretching across the east from the Gulf coast to Newfoundland. The value of $P-E$ is positive across the continent outside of the North American monsoon region with maxima along the West Coast and the East Coast as well. The mean flow moisture convergence (Fig. 1d) is partly responsible for the West Coast maximum. In contrast, transient eddy moisture flux convergence (Fig. 1h) sustains the $P-E$ maximum in the east and occurs as one part of a dipole with transient eddy moisture flux divergence over the subtropical North Atlantic Ocean and south of the Gulf Stream/North Atlantic Drift. That is, during winter, storm systems collect moisture from the ocean and converge it into the eastern part of North America (see also Shaw and Pauluis. 2012). Transient eddies actually converge moisture across all of North America, except for eastern Mexico, with the secondary maximum along the West Coast. The negative $P-E$ over Mexico is sustained by strong mean flow moisture divergence. The part of the mean flow moisture divergence due to mass divergence (Fig. 1e) is, over the Pacific and Atlantic Oceans, a fairly clear north-south pattern with moisture divergence in the subtropics and convergence in the midlatitudes, consistent with Hadley cell descent and eddy-driven midlatitude ascent. This simple pattern is not so clear over land, where it is likely that vertical motion induced by topography interrupts this pattern.

In the winter half year, $P$ is clearly related to the storm tracks, both directly via transient eddy moisture flux convergence and indirectly via mean flows (with midlatitude low-level convergence and subtropical low-level divergence) induced by eddy momentum transports. The wettest regions are therefore the Pacific Northwest at the tail end of the Pacific storm track and the eastern parts of North America impacted by the Atlantic storm track. With storm tracks much weaker over land, the interior parts of North America are drier as are the more southern latitudes equatorward of the storm track. The near all-continent transient eddy convergence of moisture can be understood, in part, as a consequence of cold temperatures and very low humidities over the continent, which allows eddies to essentially diffuse moisture in from the warmer and moister atmosphere over adjacent oceans. It is notable that, in the mean, it is only the eddies that allow for positive $P-E$ in southwestern North America where the mean flow diverges moisture. It is worth noting for later reference that in the eastern Pacific, and along the North American west coast from Oregon poleward, there is a substantial role for mean flow moisture convergence in maintaining the climatological precipitation associated with the storm-track region. This breakdown between transient and mean flow terms in cooperatively maintaining a continuous precipitation feature may be likewise noted in earlier budgets of National Centers for Environmental Prediction (NCEP)-NCAR and NCEP-U.S. Department of Energy (NCEP-2) reanalyses (Newman et al. 2012). Advection and convergence by the zonal component of the mean flow converges moisture that had been transported poleward by transient terms farther west in the storm track.

\section{b. The summer half year}

In the summer half year (Fig. 2) the pattern of $P$ across North America has a general wet east/dry west pattern in contrast to the more wet north/dry south pattern of the winter half year. This reflects the weakening and poleward shift of the storm tracks and the development of subtropical anticyclones. The wet regions are now far western Canada and the eastern regions from the Gulf of Mexico and northward east of the Appalachians. 
ERAInt, 1979-2005 Climatology, NDJFMA

a) $\overline{\bar{P}}$

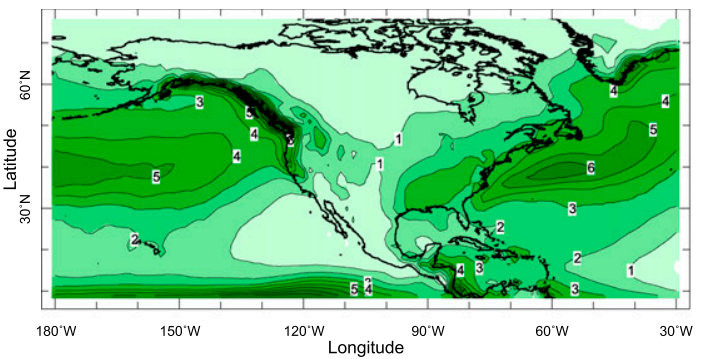

c) $\overline{\bar{P}}-\overline{\bar{E}}$

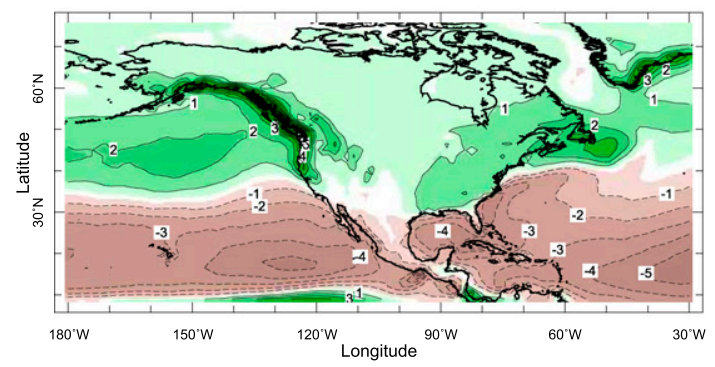

e) $-\frac{1}{g \rho_{w}} \sum_{k=1}^{K}{\overline{q_{k}} \nabla \cdot \overline{\mathbf{u}}_{k} \overline{d p}_{k}}$

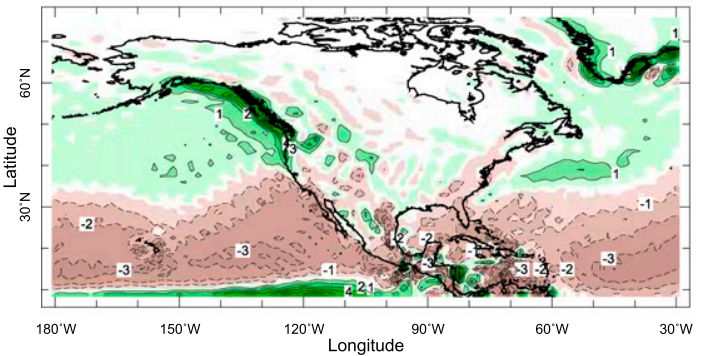

g) $-\frac{1}{g \rho_{w}} \overline{\overline{q_{s} \mathbf{u}_{s} \cdot \nabla p_{s}}}$

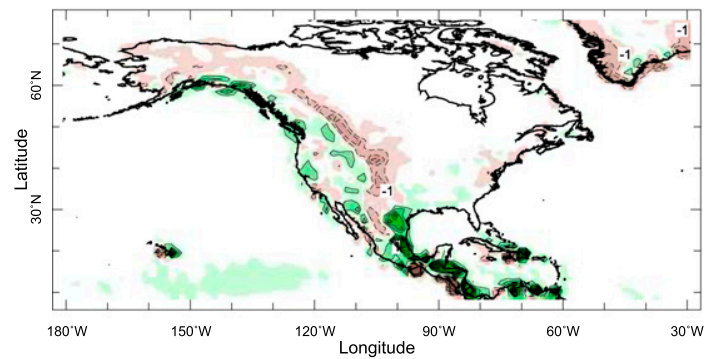

b) $\overline{\bar{E}}$

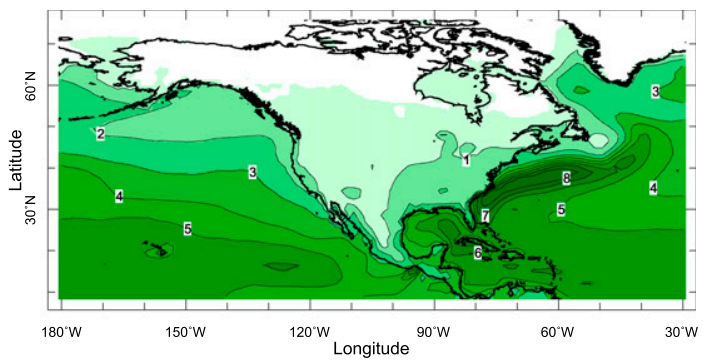

d) $-\frac{1}{g \rho_{w}} \nabla \cdot \sum_{k=1}^{K} \overline{\overline{\mathbf{u}}}_{k} \bar{q}_{k} \overline{\overline{d p}}_{k}$

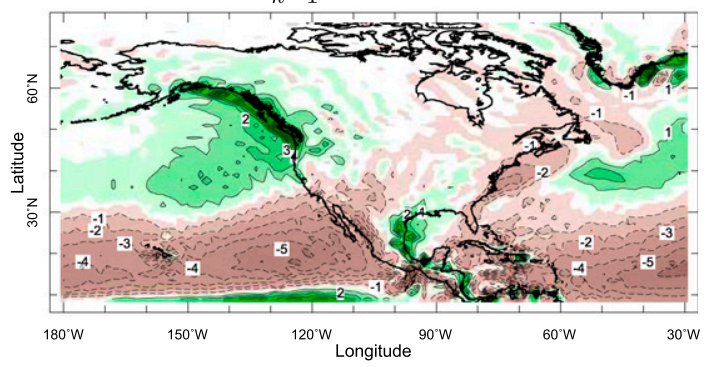

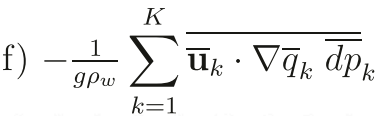

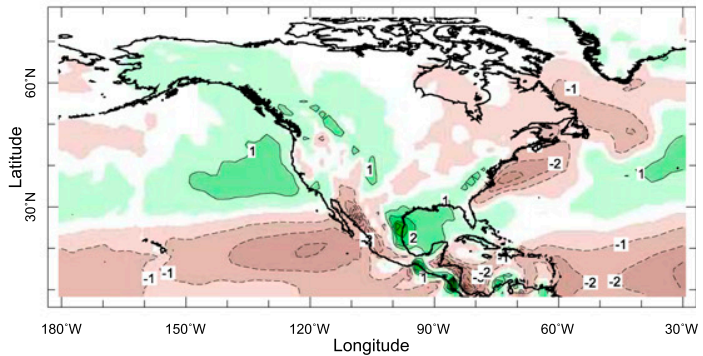

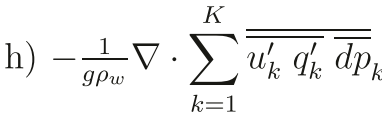



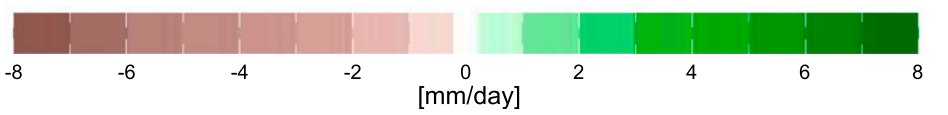

FIG. 1. The November-April half year climatological moisture budget for the North American sector from the ERA-I data: (a) $P$, (b) $E$, (c) $P-E$, (d) the moisture convergence by the mean flow with its components of (e) mass divergence and (f) advection, (g) the surface term, and (h) the transient eddy moisture convergence. 
ERAInt, 1979-2005 Climatology, MJJASO

a) $\overline{\bar{P}}$

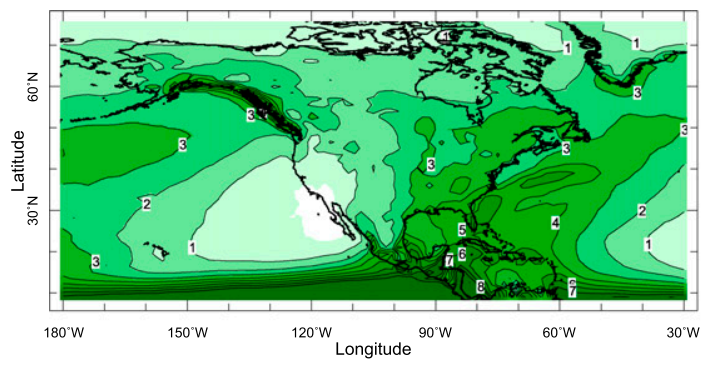

c) $\overline{\bar{P}}-\overline{\bar{E}}$

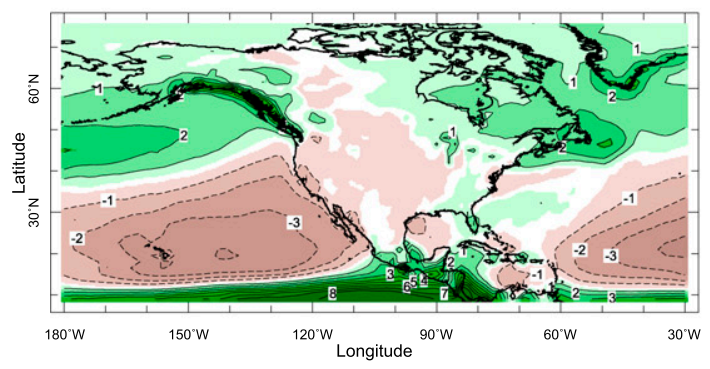

e) $-\frac{1}{g \rho_{w}} \sum_{k=1}^{K}{\overline{\bar{q}_{k}} \nabla \cdot \overline{\mathbf{u}}_{k} \overline{d p}}_{k}$



g) $-\frac{1}{g \rho_{w}} \overline{\overline{q_{s} \mathbf{u}_{s} \cdot \nabla p_{s}}}$

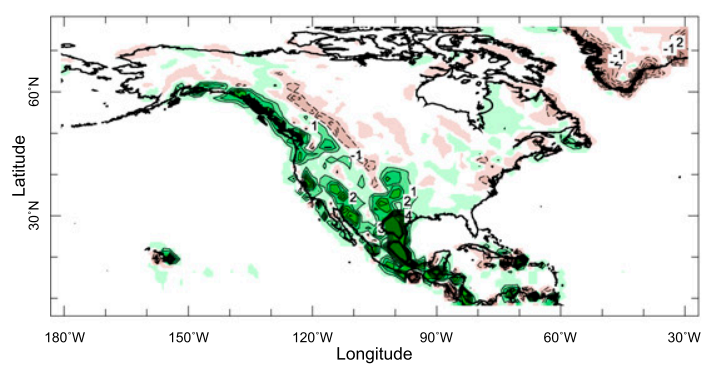

b) $\overline{\bar{E}}$

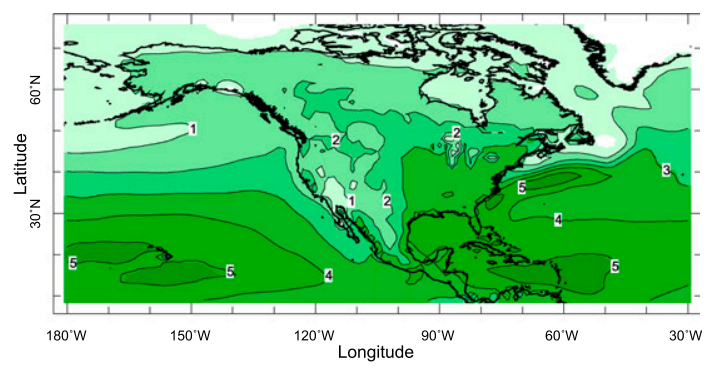

d) $-\frac{1}{g \rho_{w}} \nabla \cdot \sum_{k=1}^{K} \overline{\mathbf{u}}_{k} \bar{q}_{k} \overline{d p}_{k}$

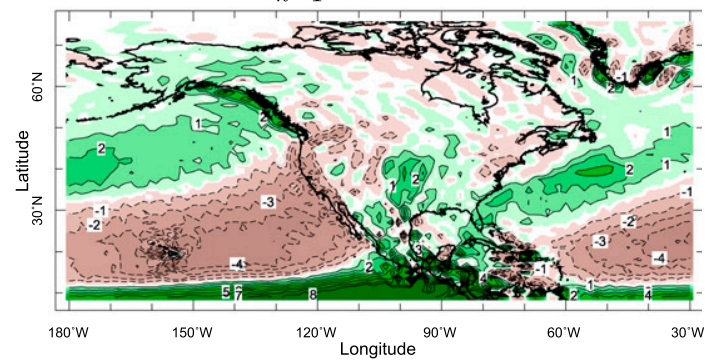

f) $-\frac{1}{g \rho_{w}} \sum_{k=1}^{K} \overline{\mathbf{u}}_{k} \cdot \nabla \bar{q}_{k} \overline{d p}_{k}$

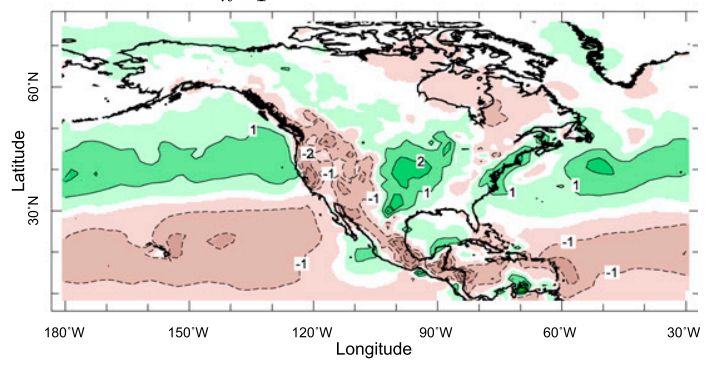

h) $-\frac{1}{g \rho_{w}} \nabla \cdot \sum_{k=1}^{K} \overline{\overline{u_{k}^{\prime} q_{k}^{\prime}}} \overline{\overline{d p}}$

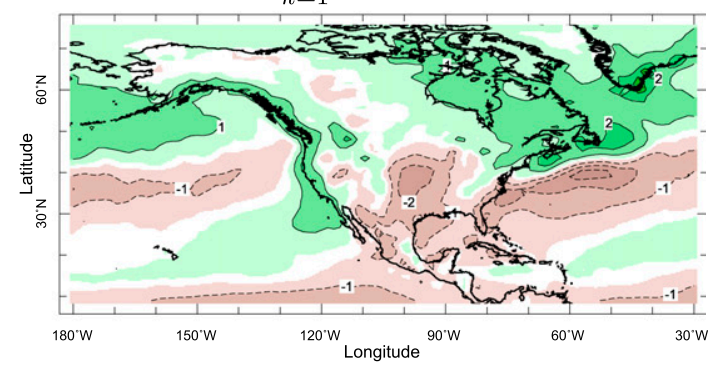

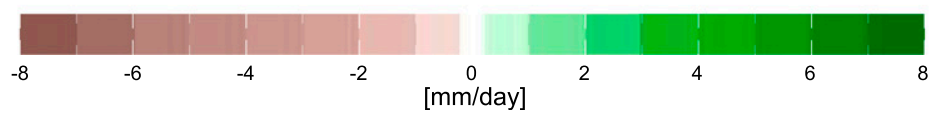

FIG. 2. As in Fig. 1, but for the May-October half year. 
Much of this $P$ is compensated for by $E$ such that, in fact, $P-E$ is negative- that is, there is atmospheric moisture divergence-across most of North America except for southern Mexico, the Pacific Northwest, northeastern Canada, and southeastern United States. Moisture export is therefore still occurring in regions where the summer is the wetter of the two half years. This is possible since a portion of the evaporated water fell as precipitation in the preceding winter half year when $E$ was very low.

In contrast to the all-wetting pattern of the winter half year, transient eddies in the summer converge moisture all along the west coast from Baja California northward and over northeastern North America, but diverge moisture from most of Mexico, the Great Plains, and southeastern United States (Fig. 2h; see also Shaw and Pauluis 2012). This is likely related to eddies acting diffusively on the strong meridional moisture gradients that develop in summer (see below). The summer half year mean flow moisture convergence dries the West Coast south of Seattle and moistens it north of there and also provides a notable wetting tendency for the central Great Plains. Advection of the moisture field (Fig. 2f) is an important part of the mean flow moisture convergence and also adopts the east wetting/west drying contrast. This is related to moistening in the central United States by southerly flow within the western flank of the Atlantic subtropical high, particularly concentrated within the Great Plains low-level jet (see also Shaw and Pauluis 2012), and drying by northerly flow across western North America on the eastern flank of the North Pacific subtropical high. The aridity of southwestern North America is therefore seen to originate from being south of the Pacific storm track in winter and on the eastern, descending northerly flow side of a subtropical high in summer. In contrast, the humid conditions across eastern North America arise from being influenced by the Atlantic storm track in winter and being on the western, ascending southerly flow side of a subtropical high in summer.

\section{Climatological North American moisture budget in the CMIP5 models}

Figures 3 and 4 show the CMIP5 multimodel mean climatological moisture budget terms. Looking at the winter half year first (Fig. 3), to first order, the models do a credible job reproducing the ERA-I budget as seen in Fig. 1. Locations of $P$ and $P-E$ maxima are quite well modeled. The models have positive $P-E$ across the entire continent, in agreement with observations except over most of Mexico. The multimodel mean, however, has $P$ too great over the U.S. Southwest (including
Southern California), which is associated with excess $E$. This excess $E$ would be sustained by the excess $P$ but could potentially feed back on the precipitation processes. It is noteworthy that the multimodel mean model moisture convergence is better simulated with respect to ERA-I in this region than the precipitation. The models sustain positive $P-E$ across the continent due in large part to transient eddy moisture convergence (Fig. $3 \mathrm{~h}$ ) although this is a little weaker, and spatially smoother, than in observations. The models also agree with observations that the mean flow diverges moisture across most of the continent but converges it over the Pacific Northwest. Contributions of the advective and mass divergent components to this are also in good agreement with the ERA-I patterns.

In the summer half year (Fig. 4) the models do a credible job of reproducing the ERA-I $P$ pattern albeit with too little $P$ over the southern Great Plains and U.S. Southeast and too small of a dry region in the southwestern United States. The models agree with ERA-I that there is moisture export (though it is underestimated) from the continent (negative $P-E$ ) except for the far U.S. Northwest and Northeast and southern Mexico. The models also agree with ERA-I that the export is sustained by mean flow moisture divergence across the west and transient eddy moisture divergence in the southern and central Great Plains (Figs. 4d,h) with the mean flow converging moisture into the latter region due to moisture advection (from the south; Fig. 4f).

These comparisons of modeled to ERA-I moisture budgets suggest that the models are successfully simulating key processes of importance to North American hydroclimate, both qualitatively and quantitatively, albeit with some exceptions. Perfect agreement should not be expected for a few reasons. First, diagnostic computation of budgets from model data archives introduces error. Principal among these is an underestimation of the transient eddy moisture fluxes and convergence as a result of using 6-hourly data (as here) as opposed to higher resolution or, ideally, model time step data (see SH for more on this). The horizontal resolution of many models may also cause many features to be smoother than in the observations. Further, ERA-I covers a particular period that, because of decadal variability, may not be representative of the long-term climatology. Also, the models do not have the spatial resolution to fully capture the influences of the complex topography of North America on hydroclimate. More comparisons of modeled and observed climate in general over North America for the historical period are available in Sheffield et al. (2013). 
CMIP5, 1979-2005 Climatology, NDJFMA

a) $\overline{\bar{P}}$

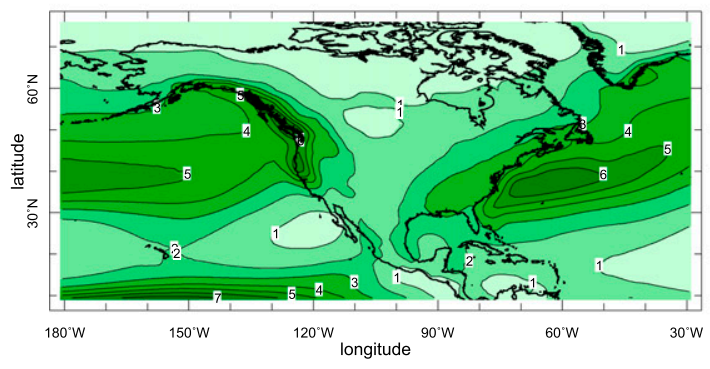

c) $\overline{\bar{P}}-\overline{\bar{E}}$
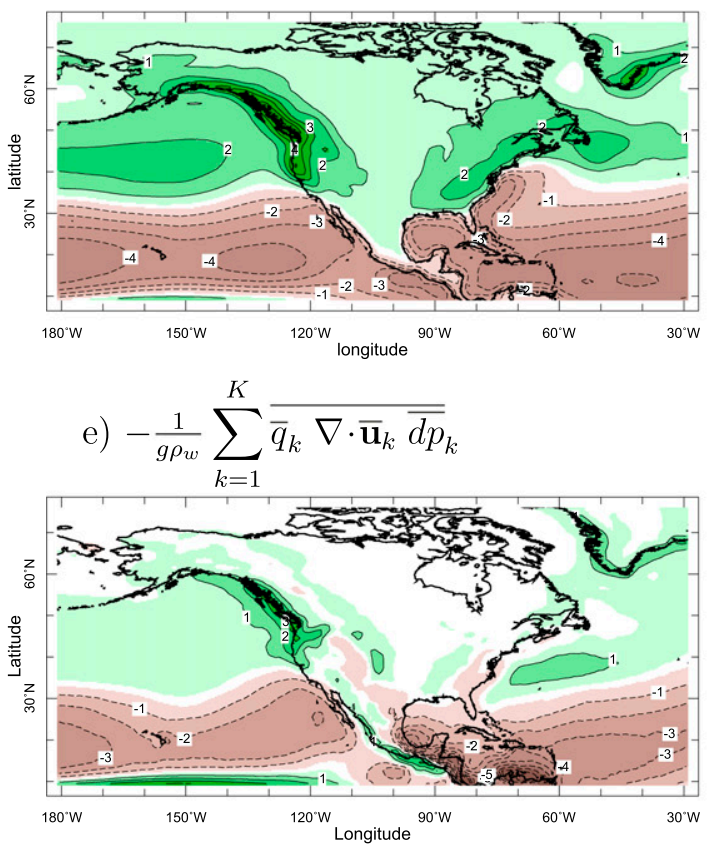

g) $-\frac{1}{g \rho_{w}} \overline{\overline{q_{s} \mathbf{u}_{s} \cdot \nabla p_{s}}}$

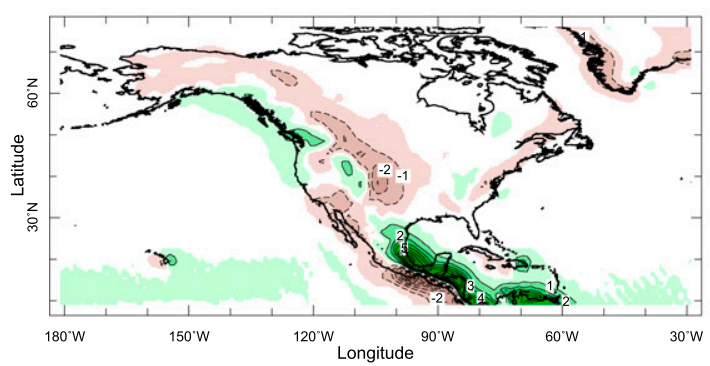

b) $\overline{\bar{E}}$

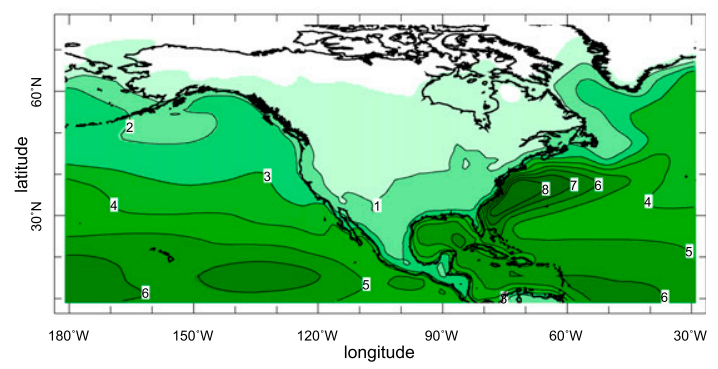

d) $-\frac{1}{g \rho_{w}} \nabla \cdot \sum_{k=1}^{K} \overline{\overline{\mathbf{u}}}_{k} \bar{q}_{k} \overline{d p}_{k}$

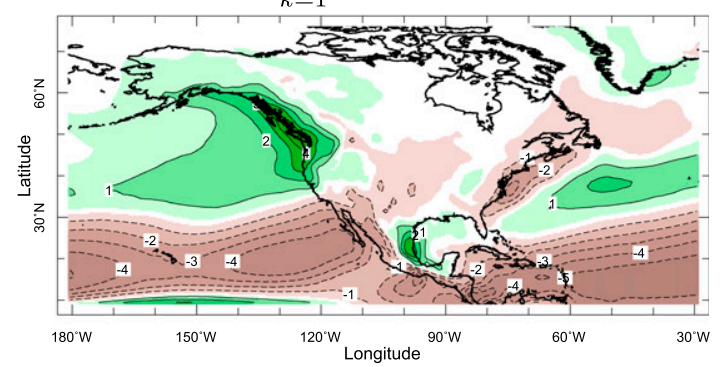

f) $-\frac{1}{g \rho_{w}} \sum_{k=1}^{K} \overline{\overline{\mathbf{u}}}_{k} \cdot \nabla \bar{q}_{k} \overline{d p}_{k}$

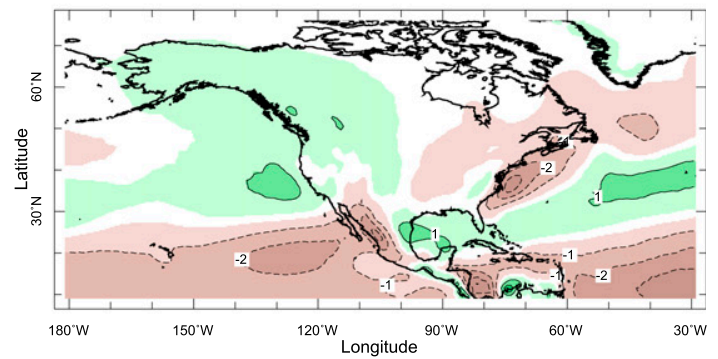

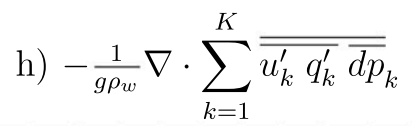

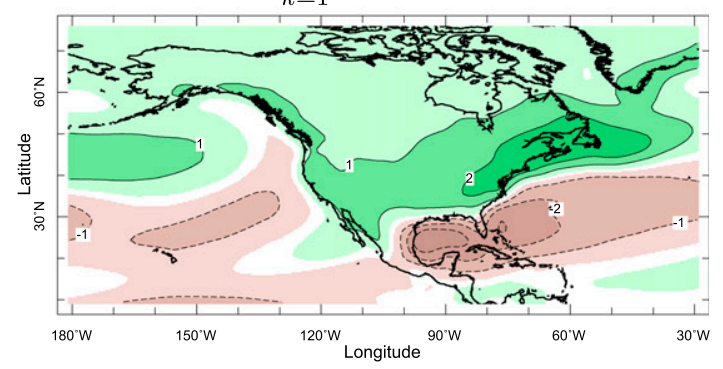

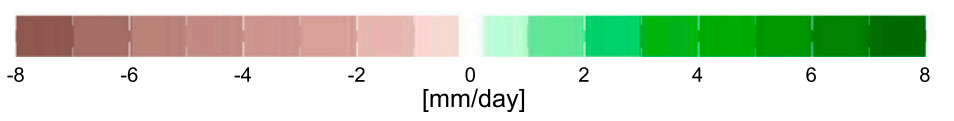

FIG. 3. As in Fig. 1, but showing the moisture budget terms for the multimodel mean of the CMIP5 models for the winter half year. 
CMIP5, 1979-2005 Climatology, MJJASO

a) $\overline{\bar{P}}$

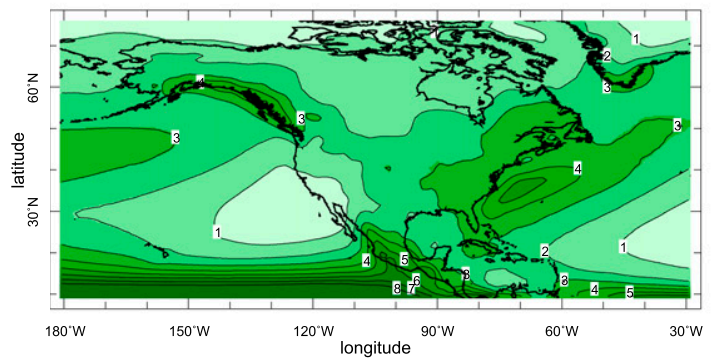

c) $\overline{\bar{P}}-\overline{\bar{E}}$

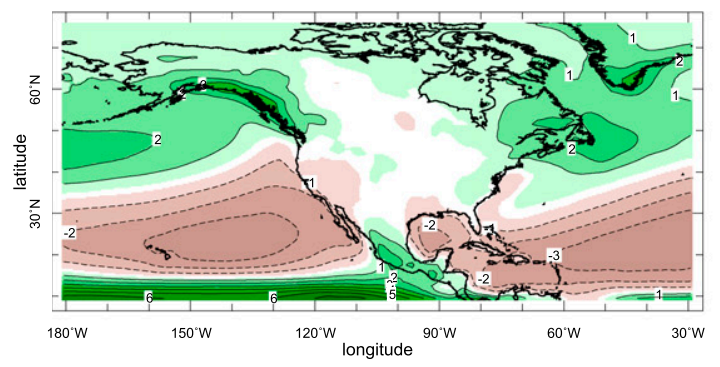

e) $-\frac{1}{g \rho_{w}} \sum_{k=1}^{K} \overline{\bar{q}}_{k} \nabla \cdot \overline{\mathbf{u}}_{k} \overline{\overline{d p}}_{k}$

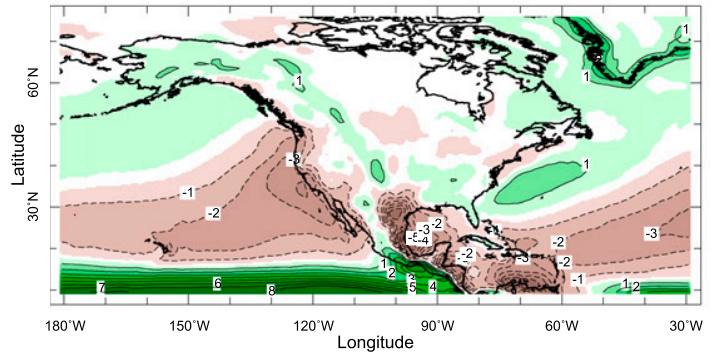

g) $-\frac{1}{g \rho_{w}} \overline{\overline{q_{s} \mathbf{u}_{s} \cdot \nabla p_{s}}}$

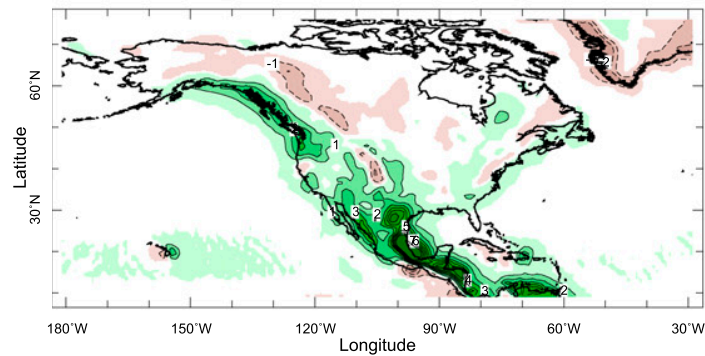

b) $\overline{\bar{E}}$

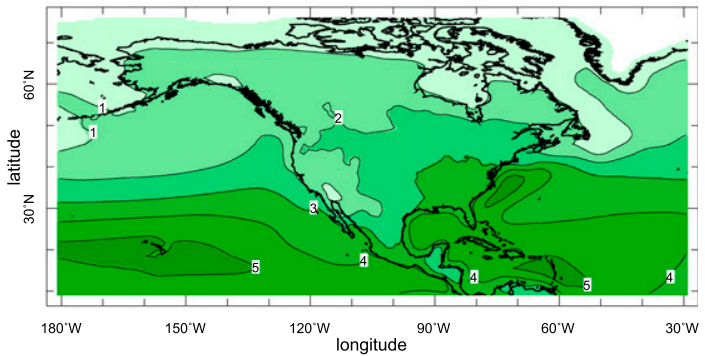

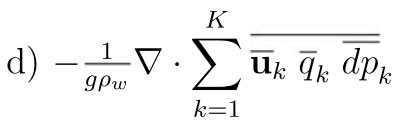

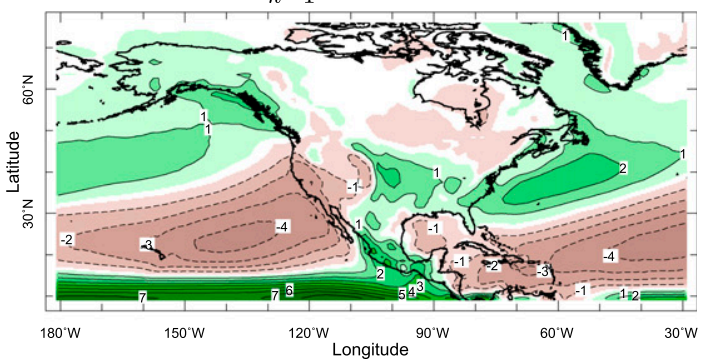

f) $-\frac{1}{g \rho_{w}} \sum_{k=1}^{K} \overline{\overline{\mathbf{u}}}_{k} \cdot \nabla \bar{q}_{k} \overline{\overline{d p}}_{k}$

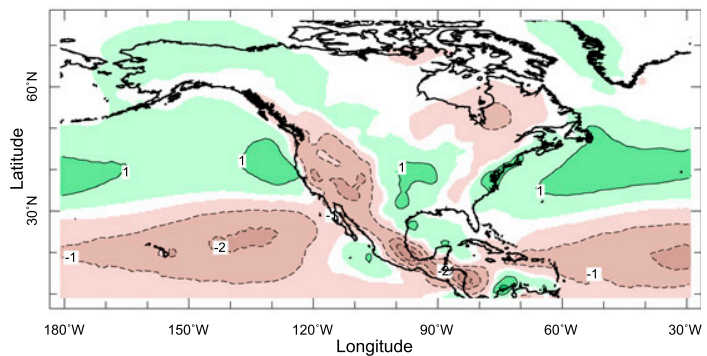

h) $-\frac{1}{g \rho_{w}} \nabla \cdot \sum_{k=1}^{K}{\overline{\overline{u_{k}^{\prime} q_{k}^{\prime}}}}_{\overline{d p}}^{k}$

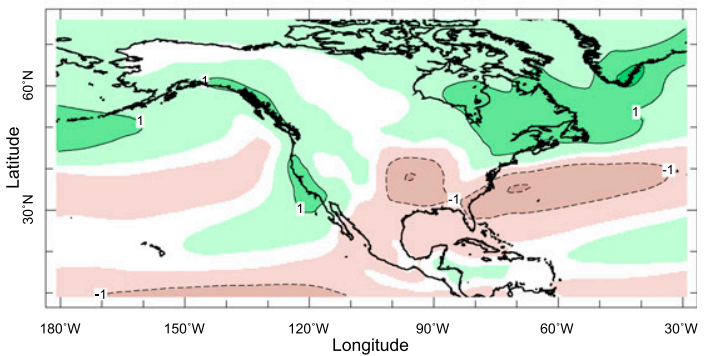

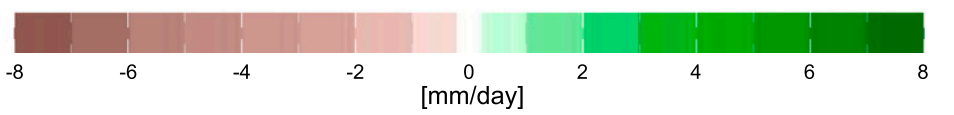

FIG. 4. As in Fig. 2, but showing the moisture budget terms for the multimodel mean of the CMIP5 models for the summer half year 


\section{Projected near-term future changes in North American hydroclimate}

\section{a. Projected hydroclimate changes in the winter half year}

Figure 5 shows the change for 2021-40 relative to 1979-2005 in the winter half year of the CMIP5 multimodel mean moisture budget. In the winter the change in $P$ is largely north-south with wetting to the north and drying to the south over Mexico and the interior southwestern United States. Following warming, $E$ increases everywhere except for Mexico such that the change in $P-E$, while also largely zonal, has a border between wetting and drying that is farther north than that of $P$ alone. However, there are some interesting zonal asymmetries with, particularly, the west coast of the United States down to central California experiencing a wetting change (Neelin et al. 2013) and a tongue of drying change extending northward into the interior southwestern United States. The regions of notable wetting under climate change are the Pacific Northwest and the northeastern United States and eastern Canada.

Causes of the $P-E$ change arise from changes in both the mean flow and transient eddy moisture convergence. The change in transient eddy moisture flux convergence (Fig. 5h) is concentrated over central and eastern North America where it represents a strengthening of the northward transport with increased moisture divergence (drying) to the south, primarily over the Atlantic Ocean, and moisture convergence (wetting) to the north over the north central and eastern United States and centraleastern Canada. The change in transient eddy moisture convergence also represents a northward shift of the twentieth-century pattern. In contrast, across western North America the north wetting/south drying pattern is sustained by a north-south pattern of mean flow moisture convergence/divergence (Fig. 5d). A predominantly zonally symmetric component of this is associated with the mean mass divergence term (Fig. 5e) while the component related to advection of humidity (Fig. 5f) introduces zonal asymmetries with wetting at the coast of southwestern North America, drying in the interior U.S. Southwest, and wetting again at the east coast of the United States. The changes in $P-E$ are governed by the same processes as the climatological $P-E$ with transients governing over eastern North America and the mean flow over western North America. The drying tendency over the Caribbean has contributions from both the mean and transients, each reasonably continuous with features affecting North America.

\section{b. Projected hydroclimate changes in the summer half year}

In the summer half year (Fig. 6) $P$ is projected to decrease across most of Mexico and across the United States from the Pacific coast to the Appalachians and increase over Canada and the eastern United States (Fig. 6a). General increases in $E$, except across the yearround drying areas in southern North America, cause, in combination with the changes in $P$, net summer drying (negative $P-E$ change) across almost the entire continent except for the core of the northern reach of the North American monsoon region, Alaska, and the far northwestern and northeastern parts of Canada. This is, like the winter half year, a roughly north wetting/south drying pattern.

Unlike for the winter, in the summer half year the change in transient eddy moisture flux convergence (Fig. 6h) plays an important role, drying to the south and wetting to the north. The transient drying is particularly strong in the central and northern Great Plains and Midwest. The dominant role of the change in mean flow moisture convergence (Fig. 6d) is to dry the western third of the United States and southwestern Canada as well as provide a strong drying in the Caribbean region. The change in mean flow moisture convergence also moistens the North American monsoon region, which is offset partially by increased transient eddy moisture divergence. Both the components associated with mass divergence (Fig. 6e) and moisture advection (Fig. 6f) contribute to the change in mean flow moisture convergence across western North America and Mexico. When this breakdown is performed, this drying is offset by the surface term (Fig. 6g), which includes orographic precipitation from flow up topography.

\section{c. Robustness of projected changes in $P$ and $P-E$}

The moisture budget calculations performed here were for the 22 models that made all the needed data available. However, the multimodel mean patterns of $P-E$ and its change are very similar to those in a larger 35-model ensemble shown here (see http://kage.ldeo. columbia.edu:81/SOURCES/.LDEO/.ClimateGroup/ .PROJECTS/.IPCC/.CMIP5/.MultiModelStatistics/). To further check the robustness of the model-projected changes, in Fig. 7 we show the number of the 22 models that agree on the sign of the change and have the same sign change as the multimodel mean. Values are only plotted where more than three-quarters of the models agree in this way. Note that if one considers a null hypothesis that the value of precipitation change for each model at a given grid point is drawn from a binomial distribution with a probability of $p=0.5$, then when 17 
a) $\Delta \overline{\bar{P}}$

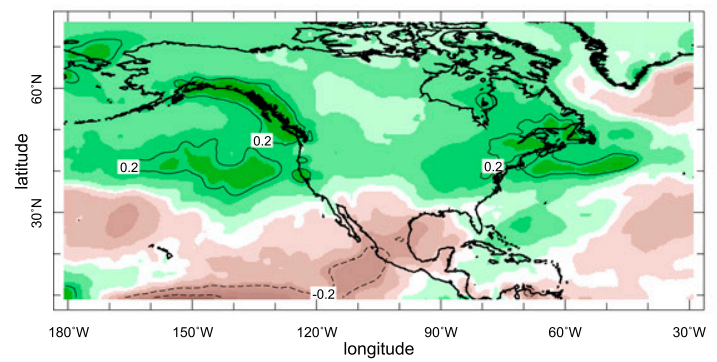

c) $\Delta(\overline{\bar{P}}-\overline{\bar{E}})$

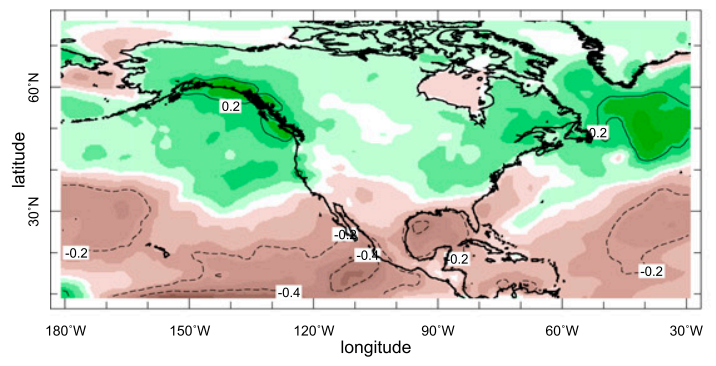

e) $-\frac{1}{g \rho_{w}} \sum_{k=1}^{K} \Delta\left(\overline{\bar{q}}_{k} \nabla \cdot \overline{\mathbf{u}}_{k} \overline{\overline{d p}}_{k}\right)$

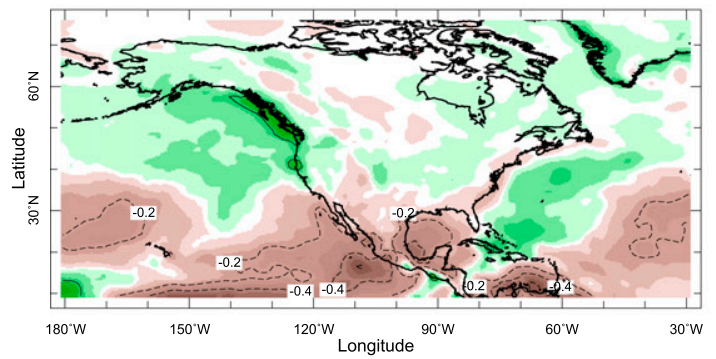

g) $-\frac{1}{g \rho_{w}} \Delta\left(\overline{\overline{q_{s} \mathbf{u}_{s} \cdot \nabla p_{s}}}\right)$
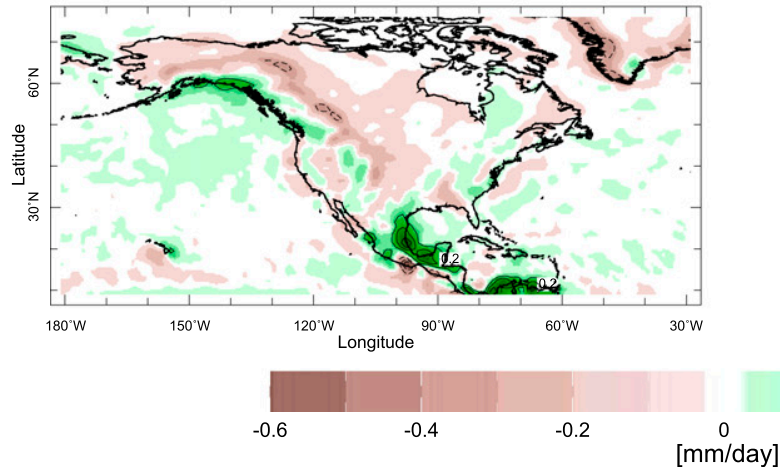

b) $\Delta \overline{\bar{E}}$

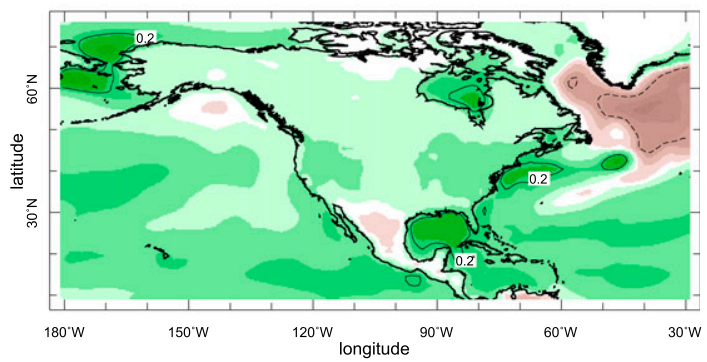

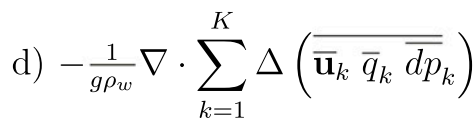

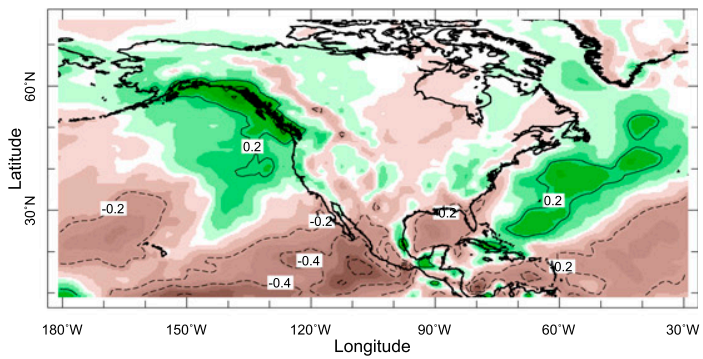

f) $-\frac{1}{g \rho_{w}} \sum_{k=1}^{K} \Delta\left(\overline{\overline{\mathbf{u}}}_{k} \cdot \nabla \bar{q}_{k} \overline{\overline{d p}}_{k}\right)$

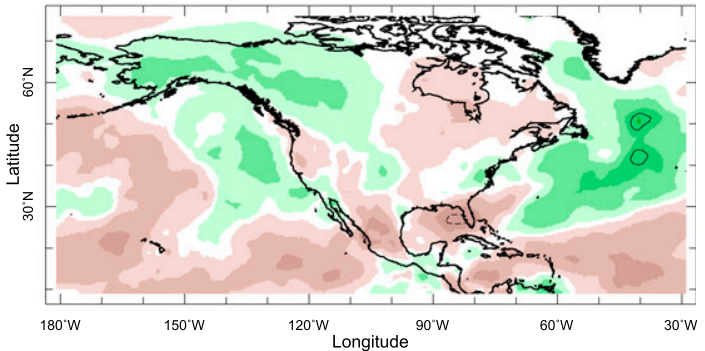

h) $-\frac{1}{g \rho_{w}} \nabla \cdot \sum_{k=1}^{K} \Delta\left(\overline{\overline{u_{k}^{\prime} q_{k}^{\prime}}} \overline{\overline{d p}}{ }_{k}\right)$

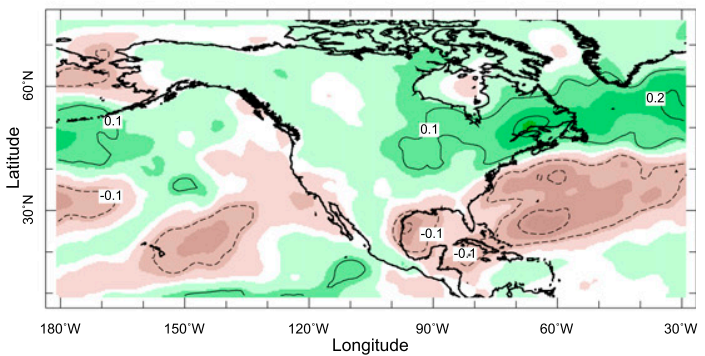

0.2

FIG. 5. The change from the 1979-2005 period to the 2021-40 period of the component of the moisture budget (mm day ${ }^{-1}$ ) for the CMIP5 multimodel mean and for the winter half year, showing the change in (a) $P$, (b) $E$, (c) $P-E$, (d) moisture convergence by the mean flow with its components changes resulting from (e) mass divergence, (f) advection, (g) the surface term, and (h) transient eddy moisture convergence. 


$$
\text { CMIP5, (2021-2040) - (1979-2005), MJJASO }
$$

a) $\Delta \overline{\bar{P}}$

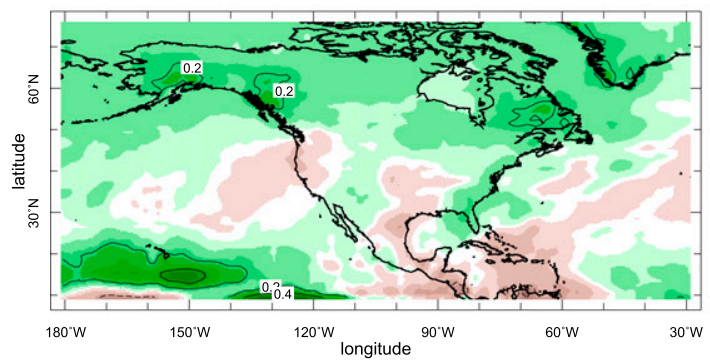

c) $\Delta(\overline{\bar{P}}-\overline{\bar{E}})$

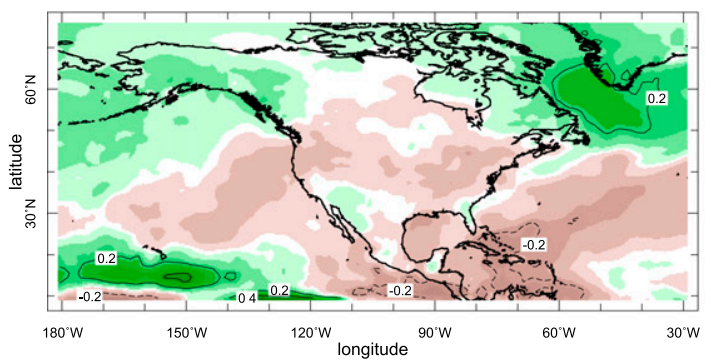

e) $-\frac{1}{g \rho_{w}} \sum_{k=1}^{K} \Delta\left(\overline{\bar{q}}_{k} \nabla \cdot \overline{\mathbf{u}}_{k} \overline{\overline{d p}}_{k}\right)$

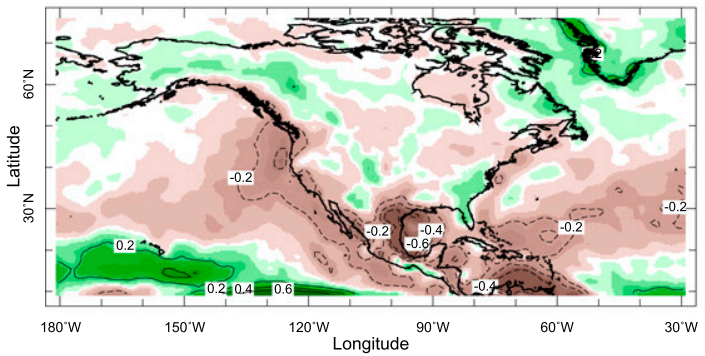

g) $-\frac{1}{g \rho_{w}} \Delta\left(\overline{\overline{q_{s} \mathbf{u}_{s} \cdot \nabla p_{s}}}\right)$

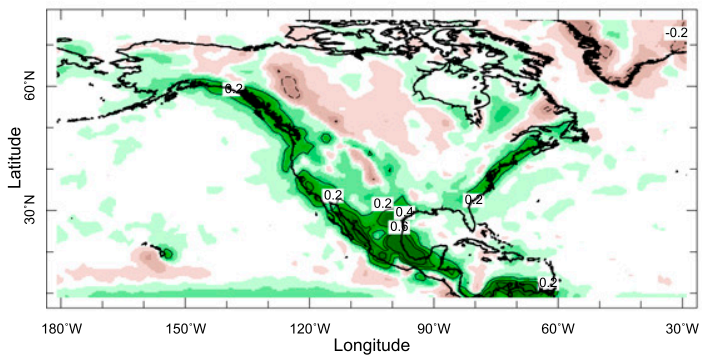

b) $\Delta \overline{\bar{E}}$

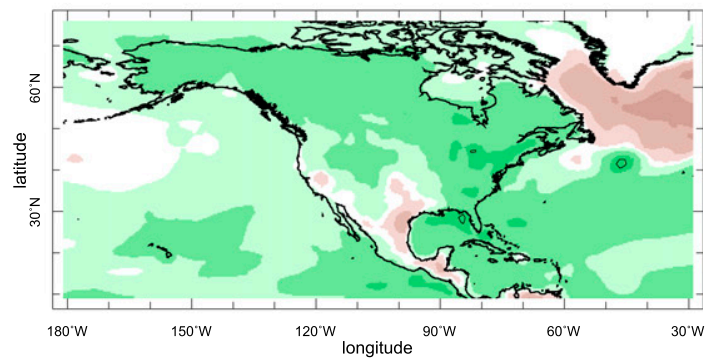

d) $-\frac{1}{g \rho_{w}} \nabla \cdot \sum_{k=1}^{K} \Delta\left(\overline{\overline{\mathbf{u}}}_{k} \bar{q}_{k} \overline{d p}_{k}\right)$

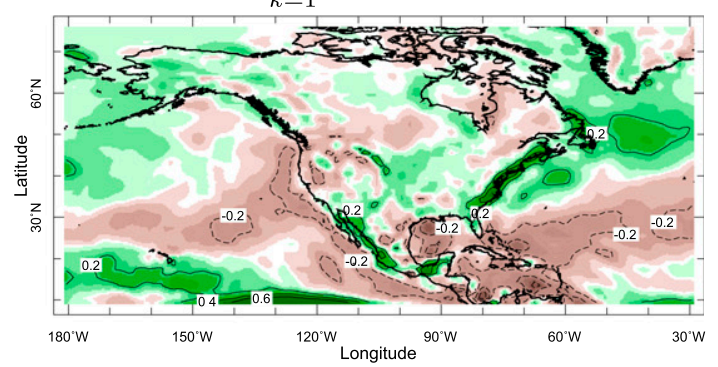

f) $-\frac{1}{g \rho_{w}} \sum_{k=1}^{K} \Delta\left(\overline{\overline{\mathbf{u}}}_{k} \cdot \nabla \bar{q}_{k} \overline{d p}_{k}\right)$

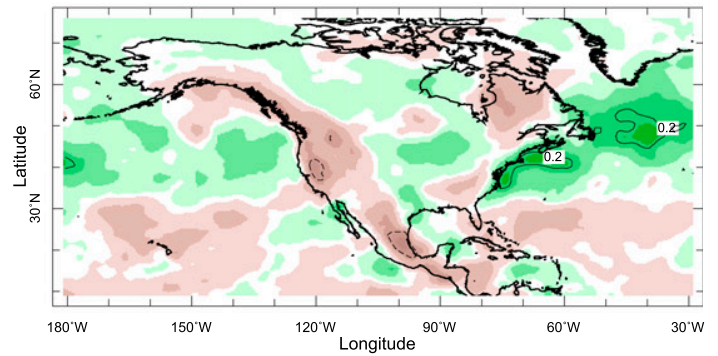

h) $-\frac{1}{g \rho_{w}} \nabla \cdot \sum_{k=1}^{K} \Delta\left(\overline{\overline{u_{k}^{\prime} q_{k}^{\prime}}} \overline{\overline{d p}}{ }_{k}\right)$

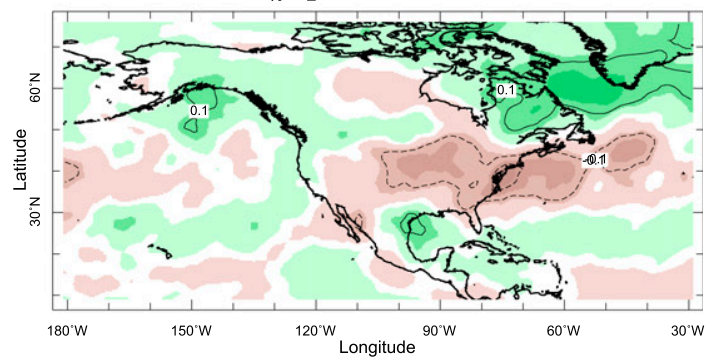

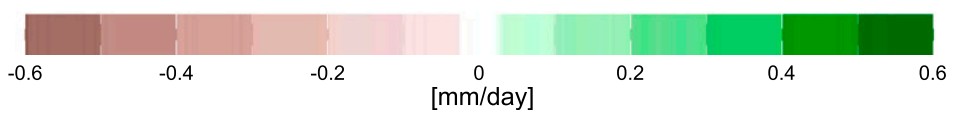

FIG. 6. As in Fig. 5, but for the summer half year. 
CMIP5, number of models matching mean, (2021-2040) - (1979-2005)

$\Delta \overline{\bar{P}} \quad$ NDJFMA

a) $\Delta \overline{\bar{P}}$

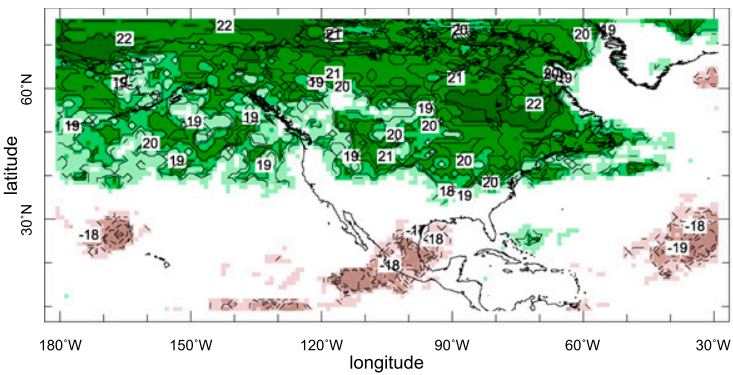

c) $\Delta(\overline{\bar{P}}-\overline{\bar{E}})$

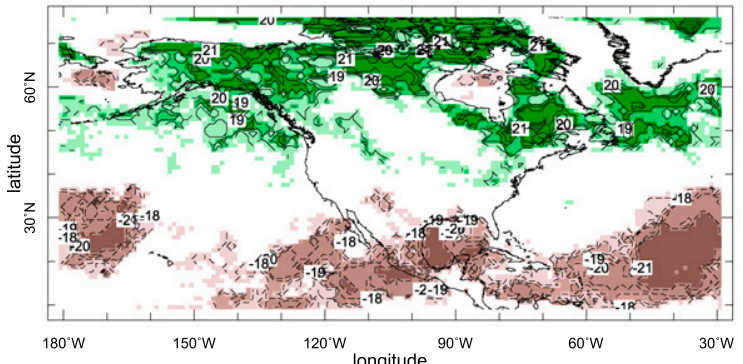

e) $-\frac{1}{g \rho_{w}} \nabla \cdot \sum_{k=1}^{K} \Delta\left(\overline{\mathbf{u}}_{k} \bar{q}_{k} \overline{d p}_{k}\right)$

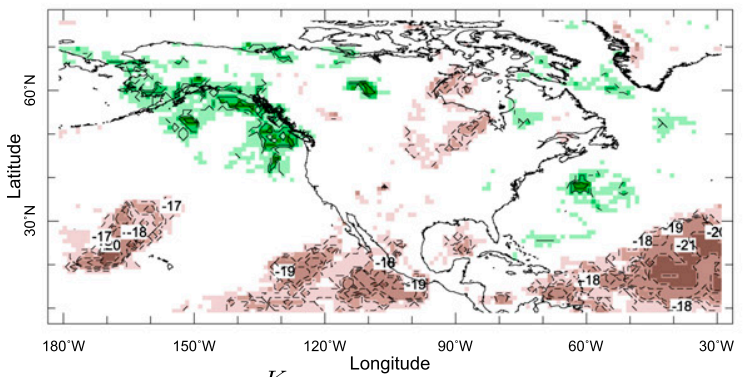

g) $-\frac{1}{g \rho_{w}} \nabla \cdot \sum_{k=1}^{K} \Delta\left({\overline{\overline{u_{k}^{\prime} q_{k}^{\prime}}}}_{\overline{d p}_{k}}^{)}\right.$

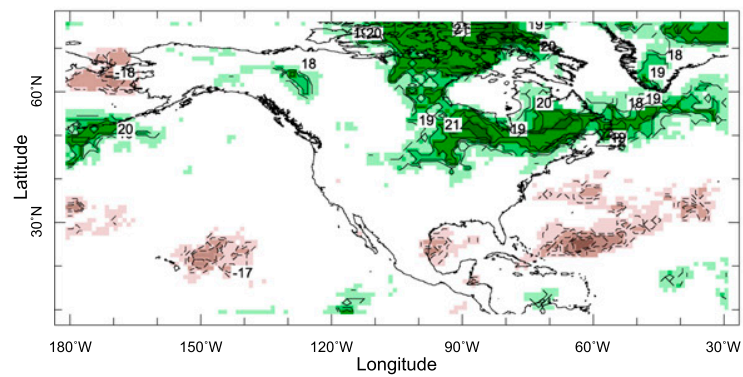

b) $\Delta \overline{\bar{P}}$

MJJASO

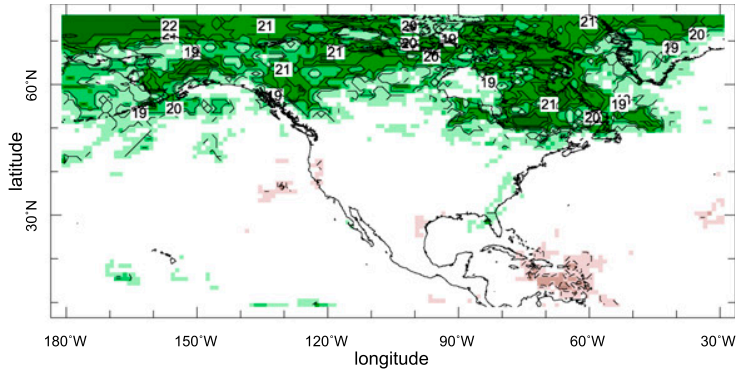

d) $\Delta(\overline{\bar{P}}-\overline{\bar{E}})$

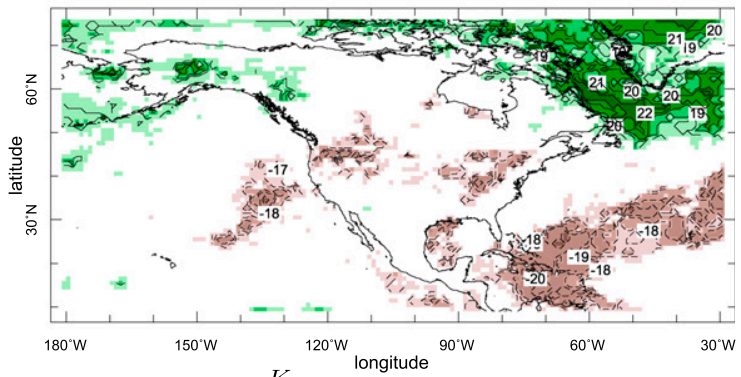

f) $-\frac{1}{g \rho_{w}} \nabla \cdot \sum_{k=1}^{K} \Delta\left(\overline{\overline{\mathbf{u}}}_{k} \bar{q}_{k} \overline{\overline{d p}}_{k}\right)$

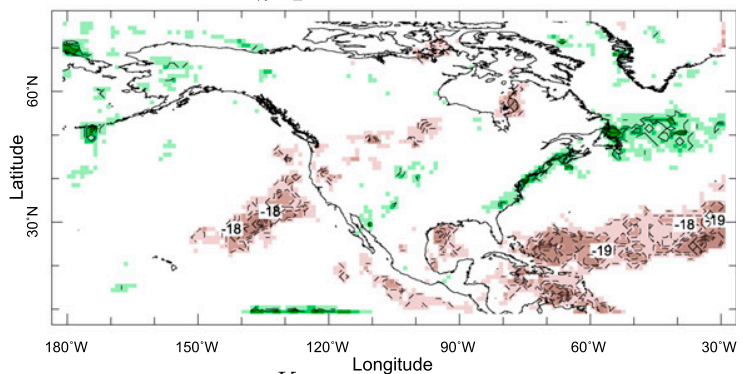

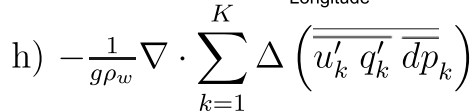

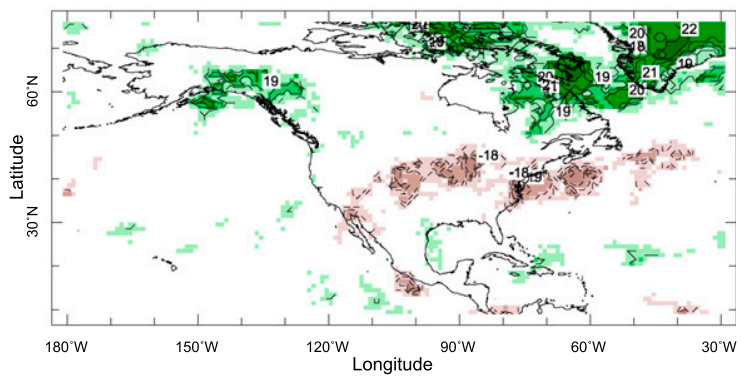

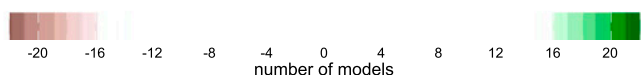

FIG. 7. The number of models that agree with the multimodel mean change in (a),(b) precipitation, (c),(d) precipitation minus evaporation, (e),(f) mean flow, and (g),(h) transient eddy moisture flux convergence for (left) winter and (right) summer half years; 22 models were used and values are only plotted when 17 or more (just over three-quarters) of the models agree on the sign of the change. 
or more models agree on sign the null hypothesis for this $50-50$ probability would be rejected at a confidence level greater than $99 \%$.

For winter half year $P$, there is substantial model agreement on increased $P$ across the northern United States and Canada from coast to coast and decreased $P$ in Mexico and the Caribbean. For winter half year $P-E$ the model agreement on the Southwest drying region extends farther into the United States than the agreement on $P$ alone. Model agreement on an increase in $P-E$ in northern regions of the United States and Canada is less than for $P$ alone, presumably because $E$ increases and offsets the increase in $P$. In the summer half year there is widespread model agreement on an increase of $P$ across Canada and a decrease of $P-E$ across the central-northern United States and southern Canada. Also shown are model agreement for the mean flow and transient eddy moisture flux convergences. There is some agreement on, in winter, mean flow drying of southern North America and transient eddy wetting of northeastern North America and, in summer, transient eddy drying of central North America. However, it should be noted that, for $P, P-E$, and the moisture convergences, less than $3 / 4$ of models agree across large areas of North America in both half years. In part this is because we have chosen a policy-relevant period to analyze, 2021-40 that begins only 7 years (after the writing of this paper), and the hydroclimate change signal at this time is still emerging. As shown in Neelin et al. (2013) and Maloney et al. (2014), the same patterns of change seen here become much larger later in the century and the level of model agreement extends over larger areas of North America.

\section{d. Contribution of humidity change and mean circulation change to the changes in mean flow moisture convergence}

So far we have shown that the changes in North American hydroclimate under global warming involve changes in both the mean flow and transient eddy moisture convergence. However, the changes associated with the mean flow could arise from either changes in specific humidity even in the absence of a change in mean flow (the so-called thermodynamic component) and/or changes in mean flow even in the absence of a change in the specific humidity (the so-called mean circulation dynamics component), as well as a nonlinear term involving changes in both mean flow and humidity, which is found to be small. Therefore we break down the changes in mean flow moisture convergence as in Eqs. (7) and (8) and show the results in Figs. 8 and 9 for the winter and summer half years, respectively.
Perhaps the simplest component is that due to the change in specific humidity combining with the unchanged mass divergent flow and this is shown in the top right of Fig. 8 for the winter half year. This is the term invoked by Chou and Neelin (2004), Held and Soden (2006), and Chou et al. (2009) to explain an in-place intensification of spatial patterns of $P-E$, the so-called rich-get-richer, poor-get-poorer, or wet-get-wetter, dryget-drier mechanism. Although changes in circulation can influence humidity change (see below), at its simplest, this term arises from a general increase in specific humidity as the atmosphere warms. This allows for an increase in mean flow moisture convergence (divergence) where the low-level mean flow is convergent (divergent). This term causes a tendency to increased $P-E$ in the tropics and high latitudes (where the mean low-level flow is convergent) and a decrease in the subtropics (where the low-level mean flow is divergent). Over the continent the rise in specific humidity causes drying over parts of interior southwestern North America and wetting over the West Coast from central California north in the winter season (Fig. 8, top right). This rich-get-richer term is the leading drying effect in the Caribbean, partially offset by other terms.

Despite the popularity of the rich-get-richer mechanism for explaining hydroclimate change, the winter drying tendency in parts of southwestern North America occurs because of the change in the mass divergent flow (Fig. 8, top left). This term does not have the simple zonal symmetry and north-south contrast of the part of the thermodynamic term associated with mass convergence and, instead, must reflect some more complex adjustment of the mean flow field. The unchanged mean flow advecting the change in specific humidity (Fig. 8, bottom right) provides a quite complex and finescale $P-E$ tendency over the eastern Pacific and North America that reflects to a large extent the complexity of the spatial pattern of low-level humidity change (see below). The change in moisture advection due to the change in advecting flow (Fig. 8, bottom left) creates a zonally varying wavelike pattern with negative $P-E$ tendency in the central Pacific, Mexico, the interior southwestern United States, and the central Atlantic and a positive $P-E$ tendency over the eastern Pacific and west and east coasts of the United States. The causes of this wave pattern in $P-E$ tendency will be examined below.

In the summer half year the increase in specific humidity combining with the unchanged mean flow (Fig. 9, top right) causes widespread drying across the far west of North America where the low-level mean flow is divergent within the subsiding branch of the North Pacific 


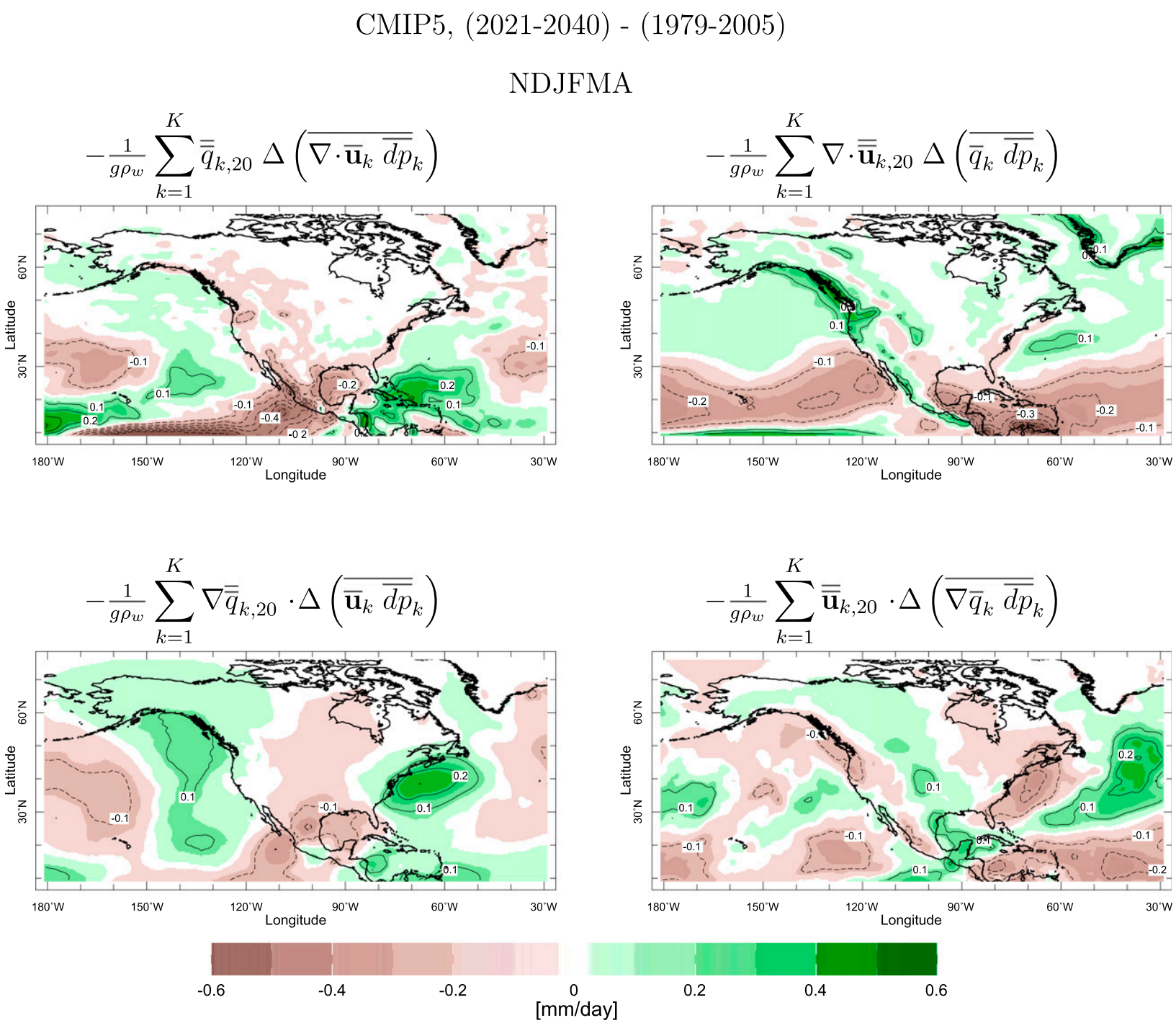

FIG. 8. The contributions to the change in the mean flow moisture convergence $\left(\mathrm{mm} \mathrm{day}^{-1}\right)$ during the winter half year for the CMIP5 multimodel mean: the (left) dynamic and (right) thermodynamic contributions to the component related to (top) divergent mean flow and (bottom) change in moisture advection.

subtropical high. The component due to the change in the mass divergent mean flow (Fig. 9, top left) causes a strong drying tendency over Mexico and the southerncentral Great Plains and also over the Pacific Northwest and northeastern Pacific but with a wetting tendency over the subtropical North Pacific. Both these terms (Fig. 9, top) contribute to the drying over the Caribbean. Advection of the change in specific humidity (Fig. 9, bottom right) causes a drying tendency over almost all of western North America but a wetting tendency over the North Pacific and the southern Great Plains. In the summer half year advection of the unchanged humidity field by the changed mean flow (Fig. 9, bottom left) provides a wetting tendency over the interior southwestern and central North America.

\section{Relating the projected changes in North American hydroclimate to changes in circulation and specific humidity}

From the previous analysis it is clear that changes in the mean flow are important to explaining changes in North American hydroclimate. It also appears that changes in the spatial patterns of the specific humidity field may be important. We will examine each in turn.

\section{a. Changes in the submonthly transient eddy field}

Figure 10 shows the climatology and change in the upper- and lower-tropospheric, submonthly, meridional velocity variance $\overline{v^{\prime 2}}$, which is a measure of storm-track 


$$
\text { CMIP5, (2021-2040) - (1979-2005) }
$$

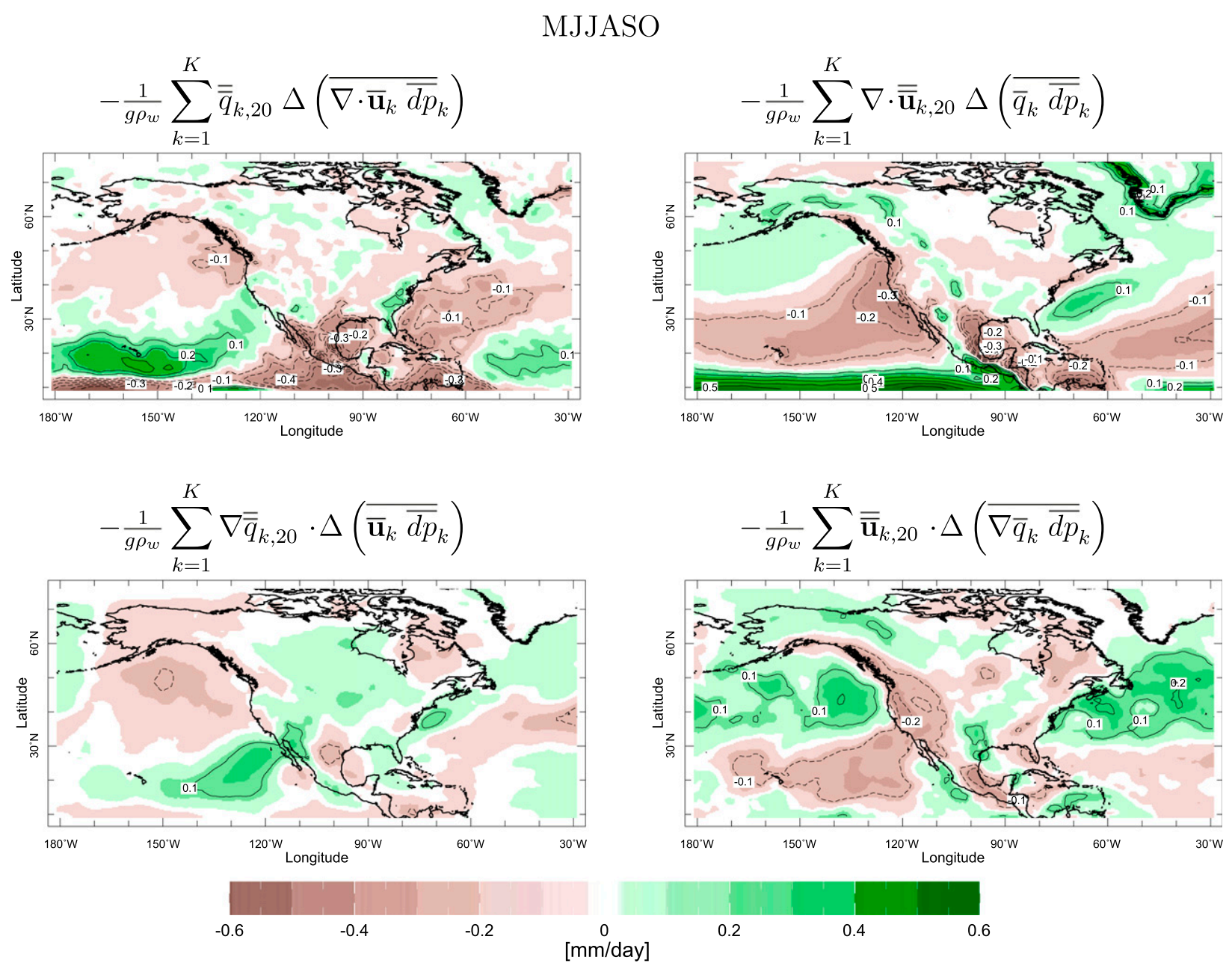

FIG. 9. As in Fig. 8, but for the summer half year.

activity for the winter and summer half years. At upper levels during the winter half year the change is primarily a poleward shift of the eddy activity. There is a decrease (on the order of $5 \%$ ) in $\overline{v^{\prime 2}}$ over southwestern North America and a weaker increase over more northerly areas of North America. The northward shift of the Atlantic eddy activity is also clear. In contrast to the upper-level poleward shift, the lower-level eddy activity decreases everywhere across North America and the surrounding oceans [in agreement with Chang et al. (2012) and Chang (2013)]. The poleward shift of upper-level eddy activity is also clear across the Pacific, North America, and the Atlantic in the summer half year. In this season eddy activity decreases across the entire United States, Mexico, and southern Canada. This decrease is also apparent at lower levels, again consistent with Chang et al. (2012). The changes in upper-troposphere eddy activity are also broadly consistent with the changes in high-pass filtered $250-\mathrm{mb}$ height variance shown by Lau and Ploshay (2013) for a simulation with a high-resolution Geophysical Fluid Dynamics Laboratory model, with the exception that that model did not have a decrease over southwestern North America in the December-February season analyzed.

It is notable that the upper-level transient eddy activity shifts poleward at all longitudes and year-round despite the changes in zonal winds (i.e., the jet stream) being more longitudinally varying, implying the lack of a one-to-one coupling between these. This is consistent with an analysis of changes in the tropospheric zonal momentum budget by Simpson et al. (2014). They show that, while the changes in zonal winds induced by a rise in greenhouse gases are quite variable in space, the 
CMIP5, (1979-2005) climatology (color), (2021-2040) - (1979-2005) (contour), $\overline{\mathbf{v}^{\prime 2}}$

NDJFMA 700mb

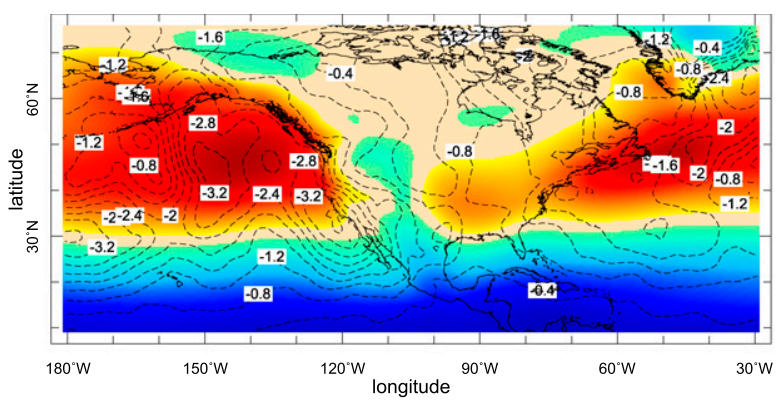

MJJASO 700mb
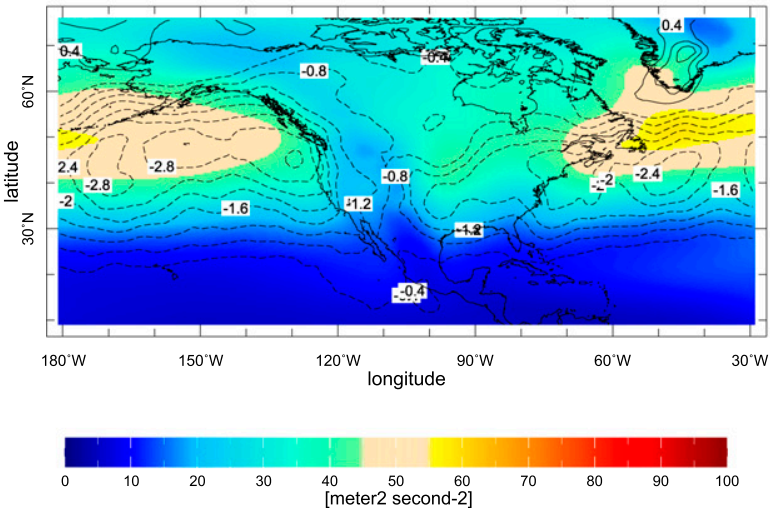

NDJFMA 250mb

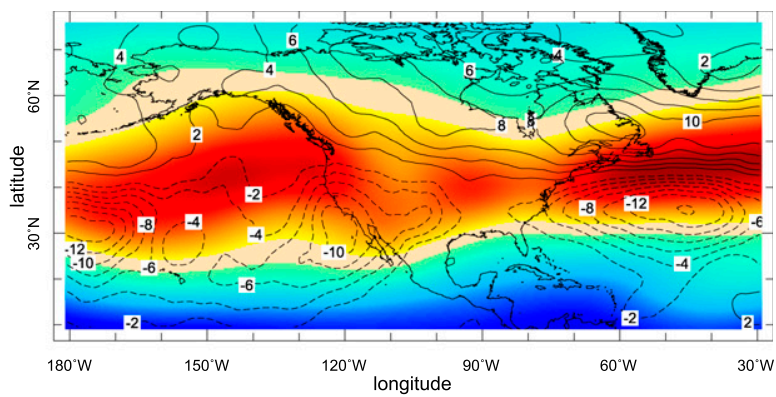

MJJASO 250mb

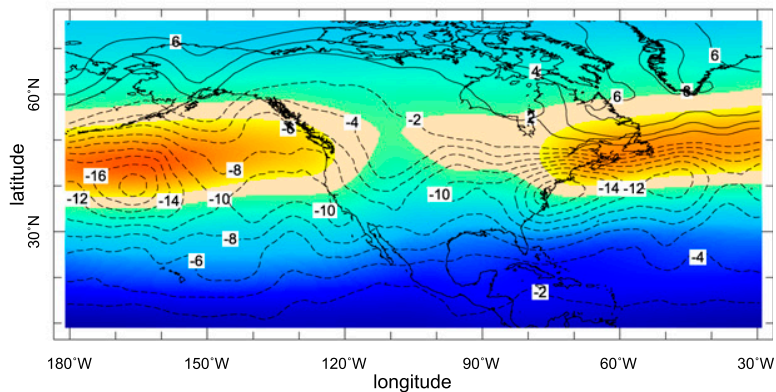

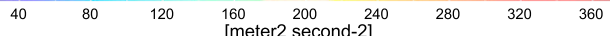

CMIP5, (1979-2005) climatology (color), (2021-2040) - (1979-2005) (contour), zg at 850mb

NDJFMA

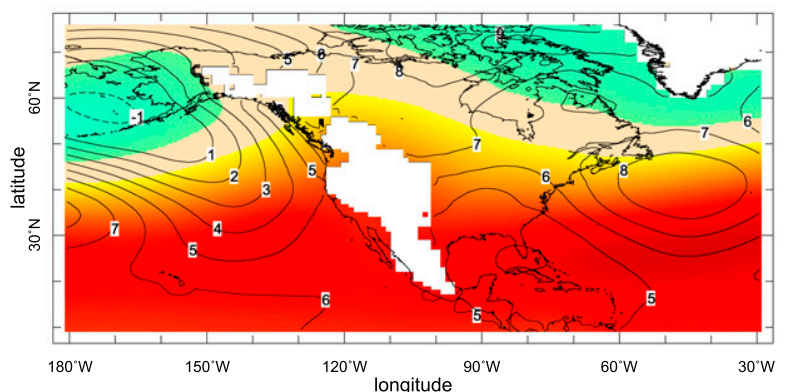

MJJASO

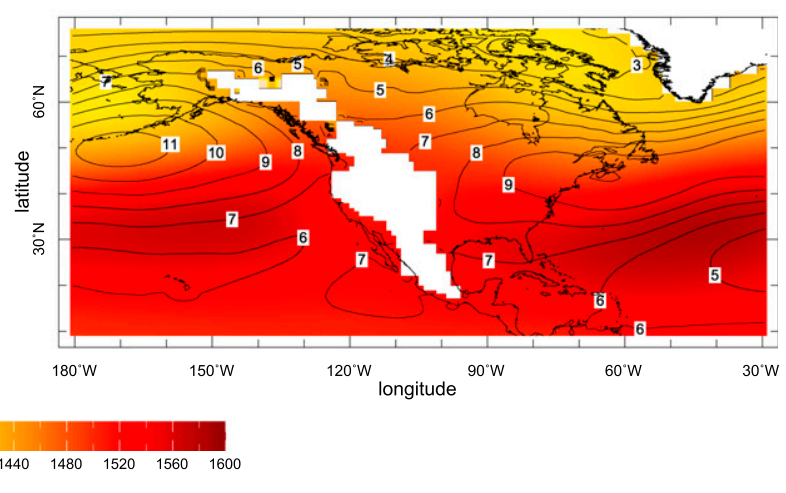

FIG. 10. The 1979-2005 climatology (colors) and change from then until 2021-40 (contours) of the multimodel mean submonthly meridional velocity variance $\left(\mathrm{m}^{2} \mathrm{~s}^{-2}\right.$ ) at (left) 700 and (right) $250 \mathrm{mb}$ for the (top) winter and (middle) summer half years and (bottom) the 850 -mb geopotential height $(\mathrm{m})$ for the (left) winter and (right) summer half years. 
driving by the high-pass filtered transient eddy activity is more zonally symmetric and would, in general, act to shift the jets poleward. That this does not occur at all longitudes and seasons is because of important momentum fluxes by the stationary components of the flow.

The main feature of change in winter half year transient eddy moisture convergence-the wetting over northeastern North America and drying over the subtropical Atlantic Ocean-despite appearing as an amplification of the preexisting pattern, is not a result of a stronger storm track. Instead it probably arises because the mean moisture gradient within which the eddies operate is stronger (see below). On the other hand, the northward shift of the transient eddy convergence/ divergence couplet over the western Atlantic-eastern North America may be explainable in terms of the northward shift of the upper-level storm activity. In the summer half year the main feature is the increased transient eddy moisture divergence from the central Great Plains. This also occurs within an environment in which the low-level eddy activity has weakened and, therefore, must also be a response to the change in the mean humidity field.

\section{b. Changes in the mean flow field}

Turning to the changes related to the mean flow, to analyze the change in advection, in Fig. 10 we also show the change in 850 -mb geopotential height from which the change in low-level flow can be inferred assuming geostrophy. The twentieth-century climatological heights are also shown. For the winter half year the $850-\mathrm{mb}$ height change shows a relative low centered over the Aleutian Islands in the North Pacific and a relative high over the central midlatitude North Atlantic. Noting that heights increase everywhere because of atmospheric warming, the change over the Atlantic might easily be interpreted as a northward extension of subtropical high pressure but, over the Pacific, the change appears as deeper low pressure on the eastern flank of, and to the south of, the Aleutian low. Southerly flow on the eastern flank of the strengthened Aleutian low correlates well in space with a wetting tendency by the anomalous flow advecting the unchanged humidity field (Fig. 8). Also, anomalous southeasterly flow around the anomalous central North Atlantic high correlates well in space with the wetting tendency over eastern North America due to changes in mean flow advecting the unchanged humidity field (Fig. 8). In between these coastal features, advective drying by a changed circulation is associated with northerly flow to the west of a Caribbean low. It is notable how far these height changes deviate from a simple zonal mean change.
The changes in heights and circulation in the summer half year are more simple and characterized by a northward expansion of the North Pacific and Atlantic subtropical highs (Li et al. 2012b). The $P-E$ tendencies over the oceans due to changes in moisture advection induced by the mean flow changes (e.g., drying over the northeastern Pacific) can be explained in terms of these changes in heights but, as noted earlier, in the summer half year the associated changes over land are small. The North Atlantic subtropical high also expands westward, providing a stronger southerly flow over the central United States, which can in turn be related to stronger northward moisture advection (Fig. 6) and the north wet/south dry $P$ change as previously noted for the CMIP3 models, and related to a stronger spring Great Plains low-level jet by Cook et al. (2008).

\section{c. Changes in the mean specific humidity field}

To complete the description of hydroclimate change over North America, Fig. 11 shows both the climatology and the change in the vertically integrated specific humidity field for the summer and winter half years. In the winter half year the change is to a large extent an amplification of the existing pattern. This follows from an assumption of approximately fixed relative humidity which, together with the nonlinear dependence of saturation humidity on temperature, implies, for a uniform temperature change, a larger increase of humidity in warmer and moister regions than in cooler and drier regions. However, the pattern of humidity change deviates from this simple relation in that there is a striking maximum extending from the Caribbean northeastward over the subtropical to midlatitude western Atlantic Ocean and another weaker tongue extending northward from the subtropical Pacific Ocean to western North America. These maxima in humidity increase are separated by a tongue of minimum increase over western North America. The winter season maxima and minima in the specific humidity increase can be explained in terms of the change in meridional winds and inferred from Fig. 10. However, to make this even clearer, in Fig. 12 we show the winter half year change in low-level $(850 \mathrm{mb})$ and upper-level $(250 \mathrm{mb}) \mathrm{me}-$ ridional velocity. The southerly flow change at the coasts is seen with northerly flow change in between over southwestern North America. Further, it is seen that this change in the mean flow is contained within a cross-Northern Hemisphere wave train that appears to originate from the subtropical northwestern Pacific. The origins of this approximately barotropic wave train, which is quite robust across the models (as shown by the stippling in Fig. 12; also the robustness and 
CMIP5, (2021-2040) - (1979-2005) (color and contour), $\frac{1}{g} \sum_{k=1}^{K} \Delta \bar{q}_{k} \overline{d p}_{k}$
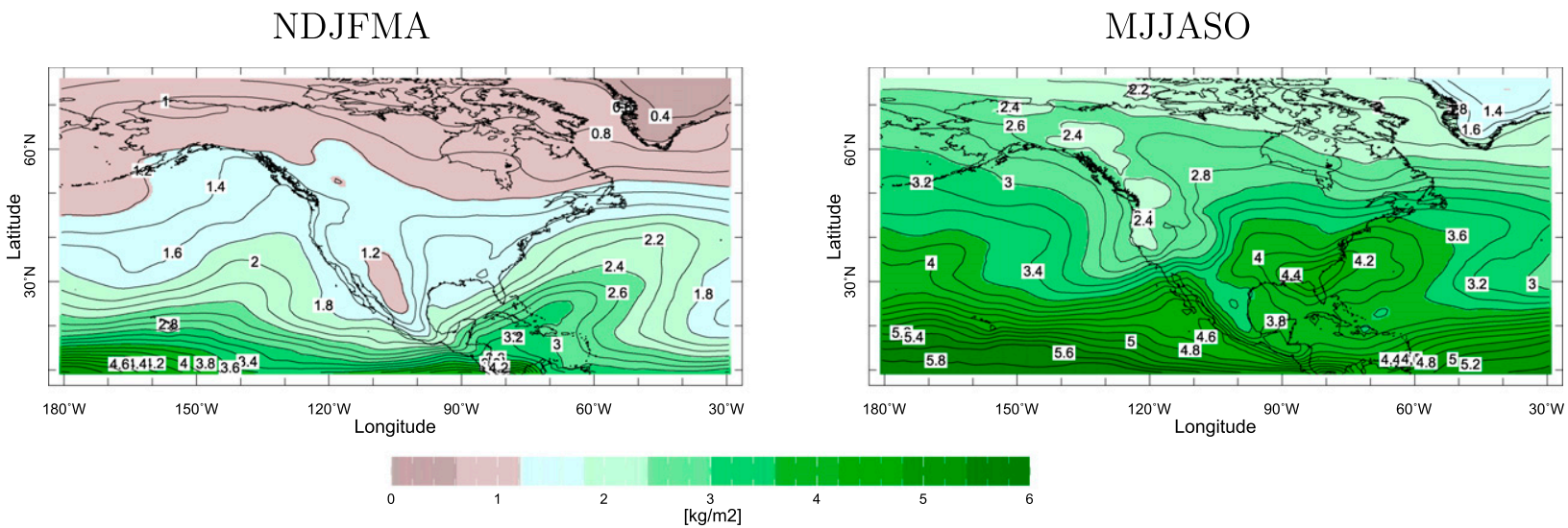

CMIP5, (1979-2005) Climatology (color and contour), $\frac{1}{g} \sum_{k=1}^{K} \Delta \bar{q}_{k} \overline{d p}_{k}$
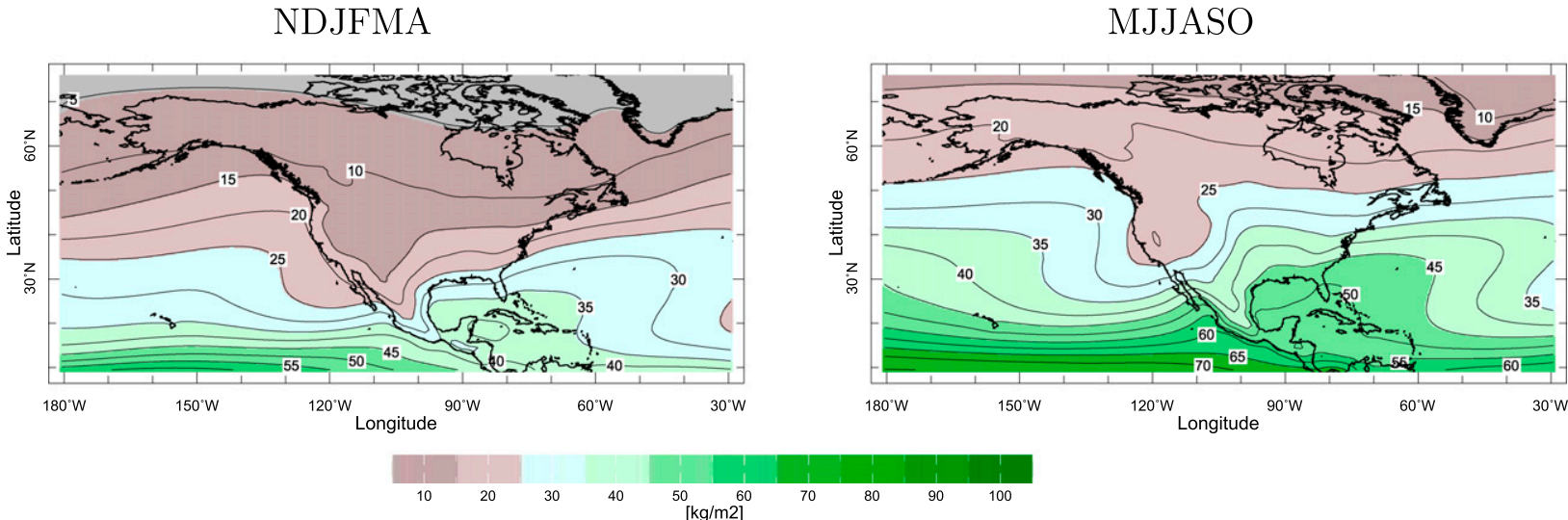

FIG. 11. The (top) change from 1979-2005 to 2021-40 and (bottom) 1979-2005 climatology in the multimodel mean surface-600-mb vertically integrated specific humidity $\left(\mathrm{kg} \mathrm{m}^{-2}\right)$ for the (left) winter and (right) summer half years.

amplitude of this wave amplifies as the century progresses; not shown), are not clear but its importance to North American hydroclimate change is obvious.

\section{Conclusions and discussion}

\section{a. Conclusions}

We have conducted a comparison of the atmospheric moisture budget over North America and surrounding ocean areas between a CMIP5 multimodel ensemble and the ERA-I data and then examined how this changes in the models between the last several decades and the period of 2021-40. The purpose is to understand the physical mechanisms that cause well-known modelprojected changes in $P-E$, especially the drying of southwestern North America, the wetting of northern regions, and the summer half year continent-wide seasonal drying. The conclusions are as follows:

- According to ERA-I, the winter half year is the moisture supply season for most of North America with positive $P-E$ everywhere except Mexico. The transient eddies dominate the atmospheric supply of moisture to the continent. The mean flow provides further moisture supply to the Pacific Northwest and diverges moisture from southwestern North America. In the summer half year most of the continent, except for far northern and southern regions, loses moisture to the atmosphere. This is despite many parts of North America having summer precipitation maxima (which must be allowed for by the greater 


\section{CMIP5, (2021-2040) - (1979-2005), $\Delta(\overline{\mathbf{v}})$ NDJFMA}
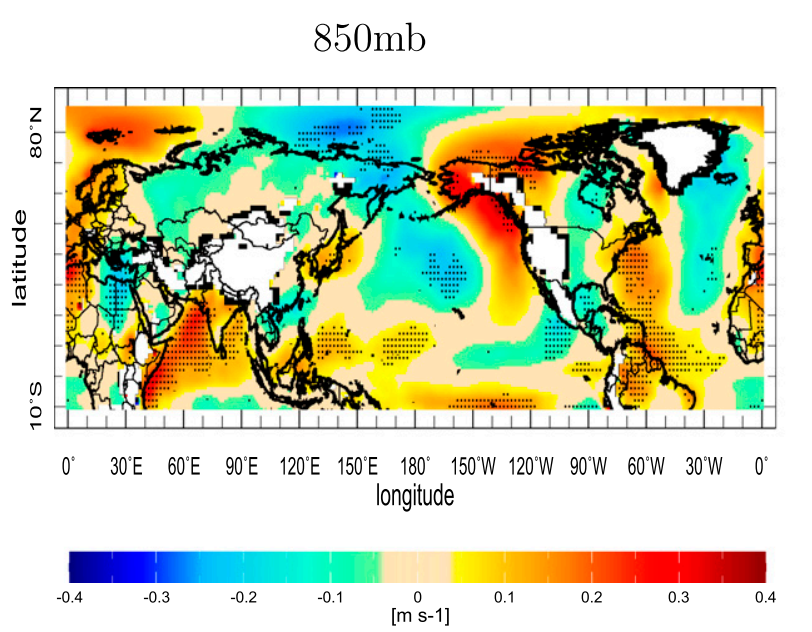

$250 \mathrm{mb}$
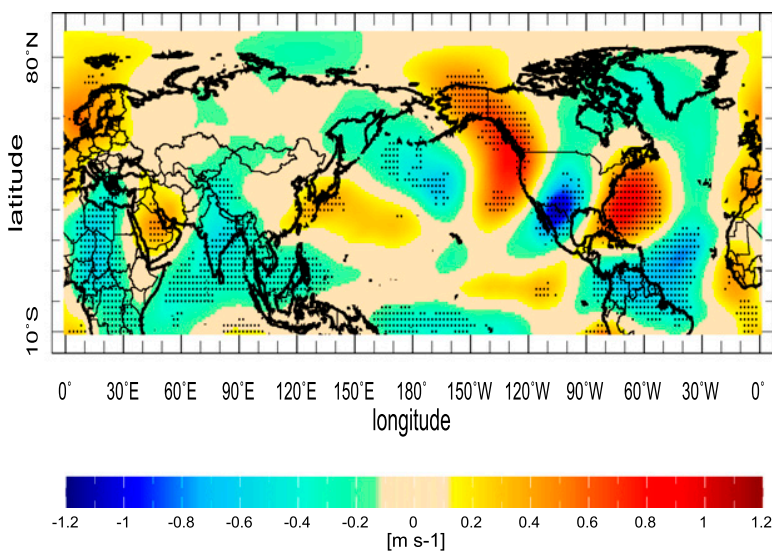

FIG. 12. The change from 1979-2005 to 2021-40 in the multimodel mean (left) 850 - and (right) 250 -mb meridional velocity ( $\mathrm{m} \mathrm{s}^{-1}$ ) for the winter half year. Stippling is where three-quarters of models agree with the multimodel mean change.

summer evapotranspiration). The summer half year atmospheric moisture divergence is accomplished by the mean flow across the western United States and by transient eddies in the central United States that offset a mean flow wetting tendency. Transient eddies in the summer continue to provide a wetting tendency to the west coast of the United States and Canada and New England and eastern Canada. These essential features of North American hydroclimate are captured by the multimodel mean of 22 CMIP5 models.

- In the winter half year the models project that Mexico and the interior southwestern and southern United States will experience drying as measured by a decrease in $P-E$ that comes from a drop in $P$ and, in the more northerly reaches of drying, an increase in $E$. The models project $P-E$ to increase over the more northern portion of North America (roughly north of $\left.35^{\circ}-40^{\circ} \mathrm{N}\right)$. The southwestern and southern winter season drying is balanced by an increase in the mean flow moisture divergence. The wetting in northeastern North America is driven by an intensification of transient eddy moisture flux convergence in the region accompanied by intensified divergence over the subtropical North Atlantic Ocean.

- The models project summer drying and atmospheric moisture export to intensify across almost the entire continent associated with increased mean flow moisture divergence across western North America and increased transient eddy moisture divergence in the central United States.

- In the winter half year, the rise in humidity combining with the unchanged divergent flow tends to intensify
$P-E$ patterns with the primary effect over the continent of generating a wetting tendency over the west coast of North America from central California northward.

- In the summer half year this term causes a widespread drying tendency over the west coast of North America and parts of Mexico and the Caribbean where the lowlevel mean flow is divergent. Year-round increased low-level mass divergence causes a drying tendency across Mexico, southwestern United States, and the Caribbean. The change in mean flow also causes, in the winter half year, advective wetting tendencies at the west and east coasts of North America with drying over southwestern North America. This zonally varying pattern of advective drying and wetting tendencies is contained within a wave that appears to propagate east from the subtropical northwest Pacific Ocean region.

- The changes in transient eddy moisture fluxes are in many regions an intensification of the existing patterns that result from increasing gradients of specific humidity while the strength of eddies in the lower troposphere, as measured by submonthly $\overline{v^{\prime 2}}$, actually weaken across much of North America. At the west coast of North America, there is a poleward shift of the winter half year storm track but changes in the mean flow contributions to $P-E$ are needed to explain the $P-E$ changes.

\section{b. Discussion}

The analysis presented here, despite the quantitative methodology, is largely descriptive of changes in 
model-projected North American hydroclimate change. For North America, a full explanation of hydroclimate change must account for 1) the rise in specific humidity, 2) spatial variations in the rise, 3 ) the changes in the divergent and nondivergent components of the mean flow and how they influence moisture divergence and advection, and 4) changes in transient eddy strength, location, and associated moisture convergence. In this regard a few key problems remain to be solved.

1) Why do the midlatitude storm tracks shift poleward in the future and, at lower levels, weaken? The shift has received much attention. A review of explanations, and a new one in terms of the tropospheric response to stratospheric changes, is offered by $\mathrm{Wu}$ et al. (2012, 2013). However, the matter is not solved, and Simpson et al. (2014) argue that changes in stationary waves are needed to explain all the zonal and seasonal variations of the mean circulation. In the same spirit, Lau and Ploshay (2013) have attributed some of the summer season zonal variations in their single model study to stationary waves forced by increasing precipitation over the eastern tropical Pacific Ocean. Chang et al. (2012) suggest that the weakening of eddy activity at low levels originates in a reduction of low-level baroclinicity, but this needs to be demonstrated.

2) Drying by increased mean flow moisture divergence, even in the absence of changes in humidity, is important for drying of southwestern North America and implies a low-level mass divergence change in the region. The dynamics of this-such as whether this is a local expression of a poleward expanded Hadley cell (as is clearly seen over the Atlantic Ocean to the east; S14) or a more local featureneed to be determined.

3) The causes of the relatively high zonal wavenumber wave that stretches across the Pacific-North AmericaAtlantic sector, wetting the west and east coasts of North America, and drying the U.S. Southwest interior, needs to be determined. This appears to originate in the subtropical northwestern Pacific but changes in diabatic heating, the mean flow that determines the orographic forcing, the Rossby wave source associated with heating, or the medium through which forced waves propagate could all, wholly or in part, be responsible. Given the importance (e.g., for California) of the hydroclimate impacts of this zonally asymmetric response pattern, work to clarify the mechanisms must be a priority.

4) The decomposition provided here, though illuminating, is not definitive. For one thing, the time scale separation between monthly and submonthly scales is quite arbitrary. Further, the separation into thermodynamic and dynamic components does not account for the coupling between the various components of the moisture budget. For example, at the west coast of North America a southerly advection change tends to increase moisture in a region where storm systems and mean flow convergence can convert it into positive $P-E$. Hence the humidity changes are, in part, induced by dynamic changes. Further, changes in the transient eddies can drive mean flow changes and associated moisture budget changes. Only a much more theoretically informed analysis, which would push understanding of extratropical circulations to more fully account for coupling between moist processes and circulation, can provide deeper insight.

Despite these suggestions for future research the current work, based on the latest model simulations, identifies more clearly how the atmospheric branch of the hydrological cycle over North America responds to greenhouse warming. The surety of rising atmospheric humidity in a warming atmosphere results in a tendency to drying in southwestern North America and wetting farther north. However, it must be acknowledged that equally important model-projected hydroclimate tendencies arise from mean and transient circulation changes that are yet to be physically explained. Understanding why these occur in models, and assessing whether, given model limitations and biases, these results are trustworthy, is key to narrowing uncertainties in projections of future hydroclimate across North America.

Acknowledgments. This work was supported by NOAA Award NA10OAR4310137 (Global Decadal Hydroclimate Variability and Change), DOE Award DE-SC0005107, and NSF Awards AGS-1243204, AGS317469 , and AGS-1102838 (JDN). We thank Dong Eun Lee for downloading the ERA-I data and ECMWF for making the reanalysis data available. We acknowledge the World Climate Research Programme's Working Group on Coupled Modelling, which is responsible for CMIP, and we thank the climate modeling groups (listed in Table 1 of this paper) for producing and making available their model output. For CMIP the U.S. Department of Energy's Program for Climate Model Diagnosis and Intercomparison provides coordinating support and led development of software infrastructure in partnership with the Global Organization for Earth System Science Portals. The moisture budget breakdowns analyzed here can be accessed at 


\section{CMIP5 Moisture Budget errors}

[1979-2005]
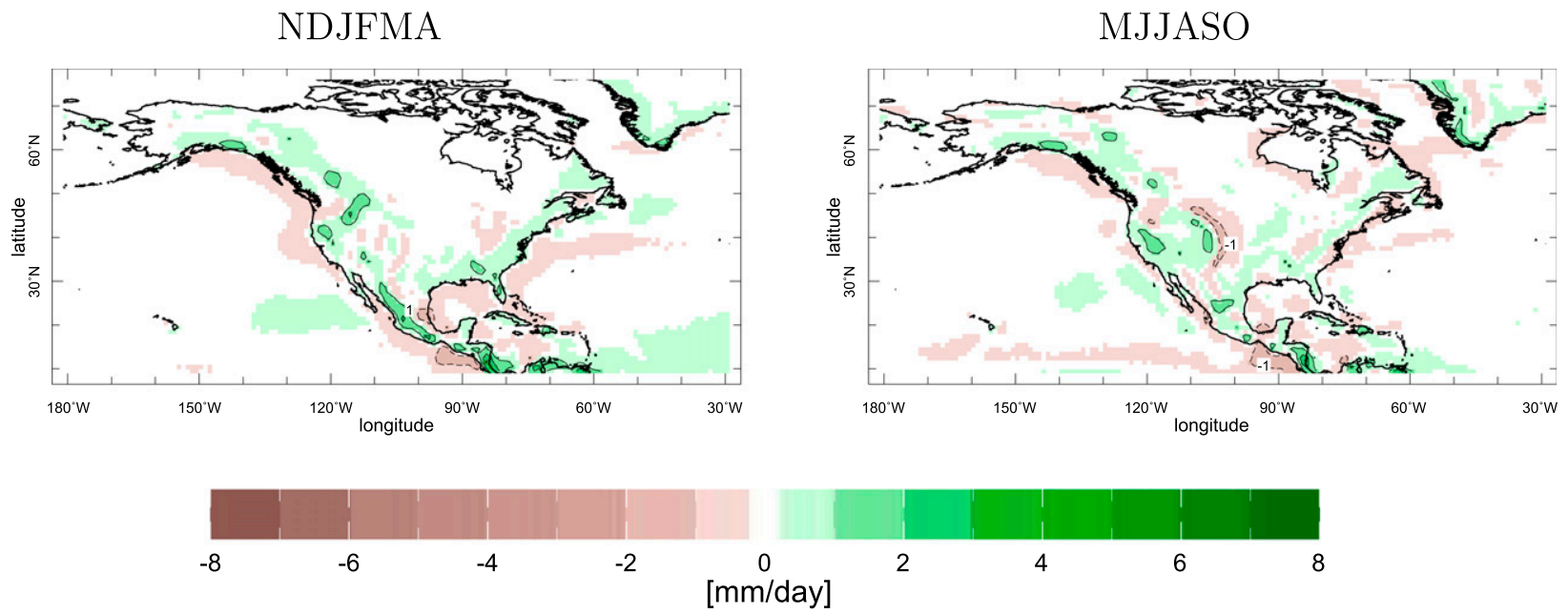

$$
[2021-2040]-[1979-2005]
$$
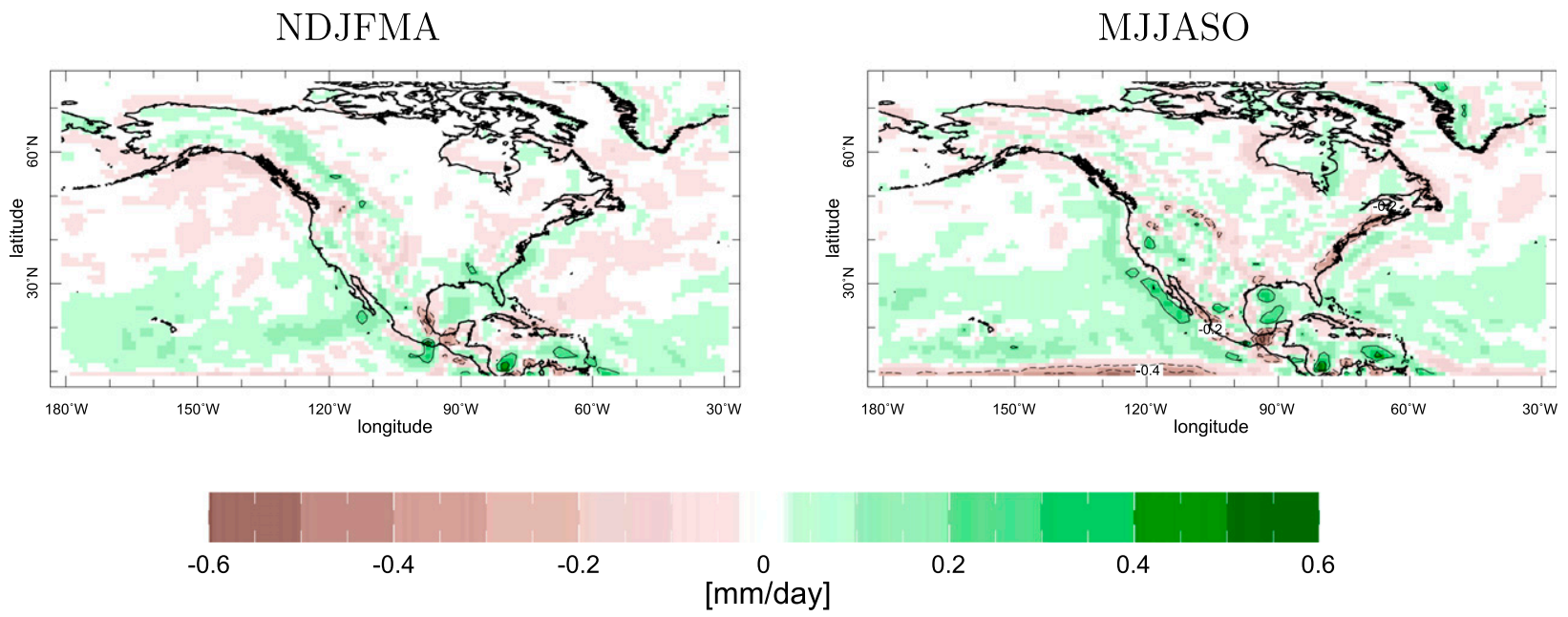

FIG. A1. The error (imbalance between the divergence of vertically integrated moisture transport and $P-E$; $\mathrm{mm} \mathrm{day}^{-1}$ ) for (top) the climatological moisture budget and (bottom) the moisture budget change from twentieth- to twenty-first-century, and shown for (left) winter and (right) summer half years. Note the difference in color scales for the climatology and the change.

http://kage.ldeo.columbia.edu:81/expert/SOURCES/ .LDEO/.ClimateGroup/.PROJECTS/.IPCC/.CMIP5/ .MoistureBudget/.

\section{APPENDIX A}

\section{Errors in the Model Moisture Budgets}

Diagnostic computation of moisture budgets in climate models leads to inevitable error since, as explained in $\mathrm{SH}$, for various reasons the budget cannot be closed. Nonetheless, following S14, here we show that the moisture budgets of the models and their change can be analyzed to extract useful information concerning the nature and physical mechanisms for hydroclimate change. The model moisture budget can be written schematically as

$$
(P-E)_{20}=-\mathrm{MC}_{20}-\mathrm{TE}_{20}+R_{20} \text { and }
$$



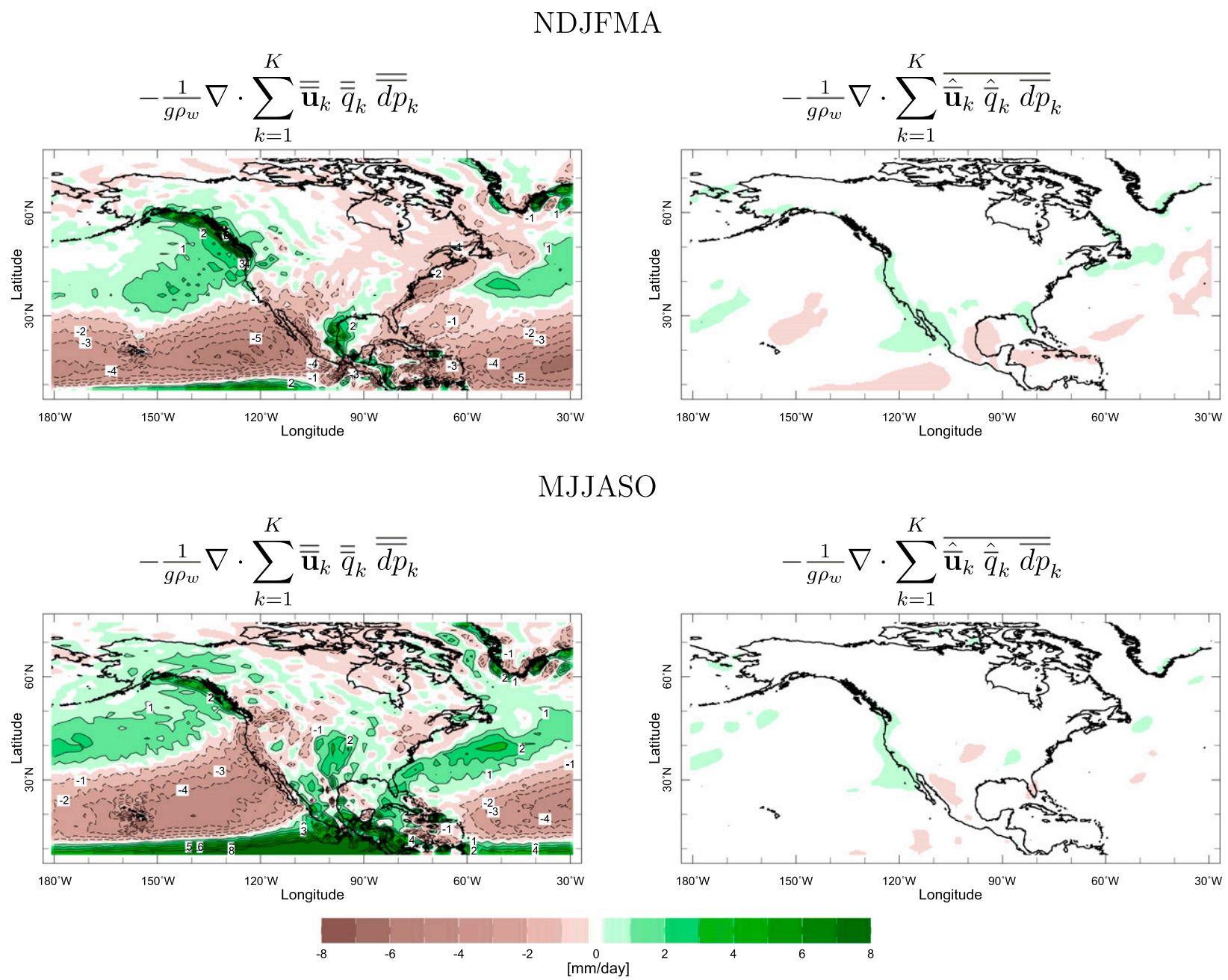

FIG. B1. Contributions to the convergence of vertically integrated mean flow moisture flux (mm day ${ }^{-1}$ ) in the ERA-I resulting from (left) the climatological mean flow combining with the climatological humidity and (right) the covariance of monthly mean anomalies of flow and humidity for (top) winter and (bottom) summer half years.

$$
(P-E)_{21}=-\mathrm{MC}_{21}-\mathrm{TE}_{21}+R_{21}
$$

where $\mathrm{MC}$ and $\mathrm{TE}$ represent the divergence of vertically integrated moisture flux by the mean flow and transient eddies respectively [as in Eq. (3)] and $R$ the residual error in the calculation within the models. The time tendency of vertically integrated moisture has been neglected as this is small compared to the error of the half year calculations presented here. Figure A1 shows the winter and summer half year multimodel mean $R_{20}$. The error is clearly very small compared to $P-E$ and the amplitude of the dominant terms in the model moisture budget (cf. Figs. 3 and 4). The error is also small compared to that shown in S14 where daily data were used as opposed to the 6-hourly data used here. This is because of the improved accuracy of estimating transient eddy moisture fluxes that the higher time resolution data allow, as noted by S14 and shown explicitly by SH for the ERA-I data. Nonetheless the error adopts the pattern of the transient eddy moisture fluxes and would presumably be even smaller if monthly means of eddy flow and humidity time step covariances had been stored in the CMIP5 archive (as recommended for future model studies by $\mathrm{SH}$ ).

The difference in the moisture budget between 202140 and $1979-2005$ is

$$
\Delta(P-E)=-\Delta(\mathrm{MC})-\Delta(\mathrm{TE})+\Delta R .
$$



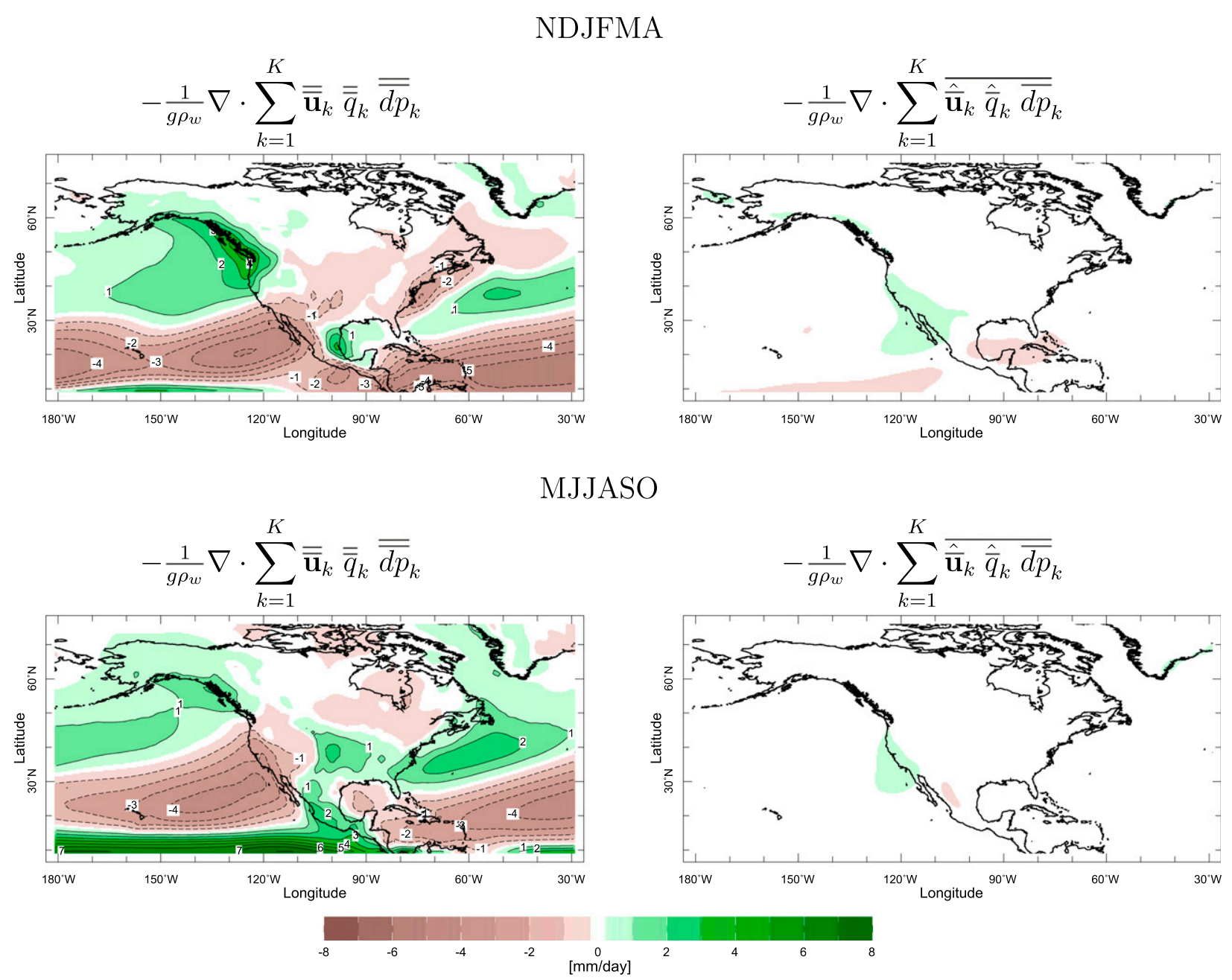

FIG. B2. As in Fig. B1, but for the mean of the CMIP5 models.

Note that $\Delta R$ is also shown in Fig. A1 for the winter and summer half years using a color scale an order of magnitude smaller than for the climatological error. The transient eddy moisture flux convergence error is of course systematic and much the same in both time periods and hence the pattern of $\Delta R$ is different to that of $R_{20}$. Also, comparing to Figs. 5 and 6, it is clear that the error in the moisture budget difference is considerably smaller than the $P-E$ difference itself and its major contributing terms. It is unlikely therefore that the error is such as to draw into question the relative importance of the different thermodynamical and dynamical mechanisms of hydroclimate change identified here. At this stage in the climate modeling enterprise such levels of error in diagnostic computations performed on archived data simply have to be accepted but are not of the magnitude that would justify inaction by workers aiming to understand climate model projections.

\section{APPENDIX B}

\section{Rectified Effect of Monthly and Longer Time Scale Variability on the Climatological ERA-I and Modeled Moisture Budgets}

The separation of winds and humidity into monthly means and departures therefrom means that the climatological mean flow moisture convergence term includes a component arising from the climatological monthly mean winds combining with the climatological monthly mean humidity and another term that is the time average of the covariance of monthly anomalies of winds and humidity. That is, 


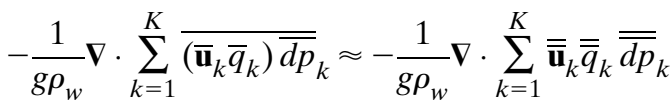

$$
\begin{aligned}
& -\frac{1}{g \rho_{w}} \nabla \cdot \sum_{k=1}^{K} \overline{\hat{\mathbf{u}}}_{k} \hat{\bar{q}}_{k} \overline{d p}_{k}
\end{aligned}
$$

where the double overbar indicates a climatological mean and the hat indicates departure of monthly means from the climatological monthly mean (e.g., $q=$ $\left.\bar{q}+q^{\prime}=\overline{\bar{q}}+\hat{\bar{q}}+q^{\prime}\right)$. The breakdown of the mean flow terms into climatology and variability for the ERA-I data is shown in Fig. B1. For both half years, it is clear that the climatology term is overwhelmingly dominant in most areas. This does not mean that the variability is weak but, instead, means that variability causes wetter and drier half years and that averaging over time cancels these out such that the climatological mean $P-E$ is not substantially altered by the presence of variability, an essentially linear situation. However, in far southwestern North America (Southern California and northwestern Mexico) in winter, where the climatological $P-E$ is very low because of close cancellation between transient eddy wetting and mean flow drying (see Fig. 1), the variability term is of the same size as the mean $P-E$. Hence this is one location where the mean hydroclimate is made wetter by the presence of monthly and longer time scale variability. Figure B2 shows the same climatology and variability breakdown for the mean of the CMIP5 models that reproduce essentially the same balances as seen in ERA-I.

\section{REFERENCES}

Berrisford, P., P. Kallberg, S. Kobayashi, D. Dee, S. Uppala, A. J. Simmons, P. Poli, and H. Sato, 2011a: Atmospheric conservation properties in ERA-Interim. Quart. J. Roy. Meteor. Soc., 137, 1381-1399, doi:10.1002/qj.864.

— , and Coauthors, 2011b: The ERA-Interim archive version 2.0. ECMWF Tech. Rep., ERA Rep. Series 1, 23 pp. [Available online at http://old.ecmwf.int/publications/library/do/references/ show?id=90276.]

Cayan, D., T. Das, D. Pierce, T. Barnett, M. Tyree, and A. Gershunov, 2010: Future dryness in the southwest United States and the hydrology of the early 21 st century drought. Proc. Natl. Acad. Sci. USA, 107, 21271-21276, doi:10.1073/ pnas.0912391107.

Chang, E. K. M., 2013: CMIP5 projection of significant reduction in extratropical cyclone activity over North America. J. Climate, 26, 9903-9922, doi:10.1175/JCLI-D-13-00209.1.

—, Y. Guo, and X. Xia, 2012: CMIP5 multimodel ensemble projection of storm track change under global warming. J. Geophys. Res., 117, D23118, doi:10.1029/2012JD018578.

Chou, C., and J. D. Neelin, 2004: Mechanisms of global warming impacts on regional tropical precipitation. J. Climate, 17, 2688-2701, doi:10.1175/1520-0442(2004)017<2688:MOGWIO>2.0.CO;2.

,-- C. Chen, and J. Tu, 2009: Evaluating the "rich-getricher" mechanism in tropical precipitation change under global warming. J. Climate, 22, 1982-2005, doi:10.1175/ 2008JCLI2471.1.

Cook, K., E. K. Vizy, Z. S. Launer, and C. M. Patricola, 2008: Springtime intensification of the Great Plains low-level jet and Midwest precipitation in GCM simulations of the twenty-first century. J. Climate, 21, 6321-6340, doi:10.1175/ 2008JCLI2355.1.

Dee, D., and Coauthors, 2011: The ERA-Interim Reanalysis: Configuration and performance of the data assimilation system. Quart. J. Roy. Meteor. Soc., 137, 553-597, doi:10.1002/ qj.828.

Held, I. M., and B. J. Soden, 2006: Robust responses of the hydrological cycle to global warming. J. Climate, 19, 5686-5699, doi:10.1175/JCLI3990.1.

Hoerling, M. P., J. Eischeid, and J. Perlwitz, 2010: Regional precipitation trends: Distinguishing natural variability from anthropogenic forcing. J. Climate, 23, 2131-2145, doi:10.1175/ 2009JCLI3420.1.

,-- A. Kumar, R. Leung, A. Mariotti, K. Mo, S. Schubert, and R. Seager, 2014: Causes and predictability of the 2012 Great Plains drought. Bull. Amer. Meteor. Soc., 95, 269-282, doi:10.1175/BAMS-D-13-00055.1.

Lau, N.-C., and J. J. Ploshay, 2013: Model projections of the changes in atmospheric circulation and surface climate over North America, the North Atlantic, and Europe in the twenty-first century. J. Climate, 26, 9603-9620, doi:10.1175/ JCLI-D-13-00151.1.

Li, W., L. Li, and Y. Kushnir, 2012a: Variation of the North Atlantic subtropical high western ridge and its implication to southeastern US summer precipitation. Climate Dyn., 39, 1401-1412, doi:10.1007/s00382-011-1214-y.

,,-- M. Ting, and Y. Liu, 2012b: Intensification of Northern Hemisphere subtropical highs in a warming climate. Nat. Geosci., 5, 830-834, doi:10.1038/ngeo1590.

MacDonald, G. M., 2010: Water, climate change, and sustainability in the southwest. Proc. Natl. Acad. Sci. USA, 107, 2125621 262, doi:10.1073/pnas.0909651107.

Maloney, E. D., and Coauthors, 2014: North American climate in CMIP5 experiments: Part III: Assessment of twenty-firstcentury projections. J. Climate, 27, 2230-2270, doi:10.1175/ JCLI-D-13-00273.1.

Neelin, J. D., M. Münnich, H. Su, J. E. Meyerson, and C. E. Holloway, 2006: Tropical drying trends in global warming models and observations. Proc. Natl. Acad. Sci. USA, 103, 6110-6115, doi:10.1073/pnas.0601798103.

_ B. Langenbrunner, J. E. Meyerson, A. Hall, and N. Berg, 2013: California winter precipitation change under global warming in the Coupled Model Intercomparison Project phase 5 ensemble. J. Climate, 26, 6238-6256, doi:10.1175/ JCLI-D-12-00514.1.

Newman, M., G. N. Kiladis, K. M. Weickman, F. M. Ralph, and P. D. Sardeshmukh, 2012: Relative contribution of synoptic and low-frequency eddies to time-mean atmospheric moisture transport, including the role of atmospheric rivers. J. Climate, 25, 7341-7361, doi:10.1175/JCLI-D-11-00665.1.

Previdi, M., and B. Liepert, 2007: Annular modes and Hadley cell expansion under global warming. Geophys. Res. Lett., 34, L22701, doi:10.1029/2007GL031243.

Scheff, J., and D. M. W. Frierson, 2012: Robust future precipitation declines in CMIP5 largely reflect the poleward expansion of model subtropical dry zones. Geophys. Res. Lett., 39, L18704, doi:10.1029/2012GL052910. 
Seager, R., and G. A. Vecchi, 2010: Greenhouse warming and the 21st century hydroclimate of southwestern North America. Proc. Natl. Acad. Sci. USA, 107, 21 277-21 282, doi:10.1073/pnas.0910856107.

- and N. Henderson, 2013: Diagnostic computation of moisture budgets in the ERA-Interim Reanalysis with reference to analysis of CMIP-archived atmospheric model data. J. Climate, 26, 7876-7901, doi:10.1175/JCLI-D-13-00018.1.

—, and Coauthors, 2007: Model projections of an imminent transition to a more arid climate in southwestern NorthAmerica. Science, 316, 1181-1184, doi:10.1126/science.1139601.

_- A. Tzanova, and J. Nakamura, 2009: Drought in the southeastern United States: Causes, variability over the last millennium, and the potential for future hydroclimate change. J. Climate, 22, 5021-5045, doi:10.1175/2009JCLI2683.1.

_ , N. Naik, and G. A. Vecchi, 2010: Thermodynamic and dynamic mechanisms for large-scale changes in the hydrological cycle in response to global warming. J. Climate, 23, 4651-4668, doi:10.1175/2010JCLI3655.1.

,$- \ldots$, and L. Vogel, 2012a: Does global warming cause intensified interannual hydroclimate variability? J. Climate, 25, 3355-3372, doi:10.1175/JCLI-D-11-00363.1.

— , N. Pederson, Y. Kushnir, J. Nakamura, and S. Jurburg, 2012b: The 1960s drought and subsequent shift to a wetter climate in the Catskill Mountains region of the New York City watershed. J. Climate, 25, 6721-6742, doi:10.1175/ JCLI-D-11-00518.1.

— M. Ming, C. Li, N. Naik, B. Cook, J. Nakamura, and H. Liu, 2013: Projections of declining surface-water availability for the southwestern United States. Nat. Climate Change, 3, 482-486, doi:10.1038/nclimate1787.

— , H. Liu, N. Henderson, I. Simpson, C. Kelley, T. Shaw, Y. Kushnir, and M. Ting, 2014: Causes of increasing aridification of the Mediterranean region in response to rising greenhouse gases. J. Climate, 27, 4655-4676, doi:10.1175/ JCLI-D-13-00446.1.
Shaw, T. A., and O. Pauluis, 2012: Tropical and subtropical meridional latent heat transports by disturbances to the zonal mean and their role in the general circulation. J. Atmos. Sci., 69, 1872-1889, doi:10.1175/JAS-D-11-0236.1.

Sheffield, J., and Coauthors, 2013: North American climate in CMIP5 experiments. Part I: Evaluation of historical simulations of continental and regional climatology. J. Climate, 26, 9209-9245, doi:10.1175/JCLI-D-12-00592.1.

Simpson, I., T. Shaw, and R. Seager, 2014: A diagnosis of the seasonally and longitudinally varying midlatitude circulation response to global warming. J. Atmos. Sci., 71, 2489-2515, doi:10.1175/JAS-D-13-0325.1.

Solomon, S., D. Qin, M. Manning, Z. Chen, M. Marquis, K. Averyt, M. M. B. Tignor, and H. L. Miller Jr., 2007: Climate Change 2007: The Physical Science Basis. Cambridge University Press, 996 pp.

Taylor, K. E., R. J. Stouffer, and G. A. Meehl, 2012: An overview of CMIP5 and the experiment design. Bull. Amer. Meteor. Soc., 93, 485-498, doi:10.1175/BAMS-D-11-00094.1.

Vano, J. A., and Coauthors, 2014: Understanding uncertainties in future Colorado River streamflow. Bull. Amer. Meteor. Soc., 95, 59-78, doi:10.1175/BAMS-D-12-00228.1.

Wehner, M., D. R. Easterling, J. H. Lawrimore, R. R. Heim, R. S. Vose, and B. D. Santer, 2011: Projections of future drought in the continental United States and Mexico. J. Hydrometeor., 12, 1359-1377, doi:10.1175/2011JHM1351.1.

Wu, Y., R. Seager, M. Ting, N. Naik, and T. Shaw, 2012: Atmospheric circulation response to an instantaneous doubling of carbon dioxide. Part I: Model experiments and transient thermal response in the troposphere. J. Climate, 25, 28622879, doi:10.1175/JCLI-D-11-00284.1.

,,,--- , and,- 2013 : Atmospheric circulation response to an instantaneous doubling of carbon dioxide. Part II: Atmospheric transient adjustment and its dynamics. J. Climate, 26, 918-935, doi:10.1175/JCLI-D-12-00104.1. 